\title{
The Impact of Steroidal Glycoalkaloids on the Physiology of Phytophthora infestans, the Causative Agent of Potato Late Blight
}

\author{
Paul Dahlin,, ${ }^{1,2}$ Marion C. Müller, ${ }^{1,2}$ Sophia Ekengren,, ${ }^{1,2}$ Lauren S. McKee, ${ }^{1,3}$ and Vincent Bulone ${ }^{1,4}$ \\ ${ }^{1}$ Division of Glycoscience, School of Biotechnology, Royal Institute of Technology (KTH), AlbaNova University Centre, 10691 \\ Stockholm, Sweden; ${ }^{2}$ Department of Ecology, Environment and Plant Sciences, Stockholm University, 10691 Stockholm, \\ Sweden; ${ }^{3}$ Wallenberg Wood Science Centre, Division of Glycoscience, School of Biotechnology, Royal Institute of Technology \\ (KTH), AlbaNova University Centre, 10691 Stockholm, Sweden; and ${ }^{4}$ ARC Centre of Excellence in Plant Cell Walls and School \\ of Agriculture, Food and Wine, The University of Adelaide, Waite Campus, Urrbrae, SA 5064 Australia
}

Accepted 29 March 2017.

\begin{abstract}
Steroidal glycoalkaloids (SGAs) are plant secondary metabolites known to be toxic to animals and humans and that have putative roles in defense against pests. The proposed mechanisms of SGA toxicity are sterol-mediated disruption of membranes and inhibition of cholinesterase activity in neurons. It has been suggested that phytopathogenic microorganisms can overcome SGA toxicity by enzymatic deglycosylation of SGAs. Here, we have explored SGA-mediated toxicity toward the invasive oomycete Phytophthora infestans, the causative agent of the late blight disease in potato and tomato, as well as the potential for SGA deglycosylation by this species. Our growth studies indicate that solanidine, the nonglycosylated precursor of the potato SGAs $\alpha$-chaconine and $\alpha$-solanine, has a greater physiological impact than its glycosylated forms. All of these compounds were incorporated into the mycelium, but only solanidine could strongly inhibit the growth of $P$. infestans in liquid culture. Genes encoding several glycoside hydrolases with potential activity on SGAs were identified in the genome of $P$. infestans and were shown to be expressed. However, we found no indication that deglycosylation of SGAs takes place. We present additional evidence for apparent host-specific adaptation to potato SGAs and assess all results in terms of future pathogen management strategies.
\end{abstract}

Crop plants are exposed to a wide range of pests and pathogens in natural and agricultural environments. One of the most devastating plant pathogens is the oomycete Phytophthora infestans. The oomycetes are a group of filamentous organisms closely related to the brown algae and diatoms (Kamoun et al. 2015) and are classified in the Stramenopiles phylum. $P$. infestans is one of the most destructive pathogens of solanaceous crop plants, causing the late blight disease, which leads to lesions on foliage and rotting of potato tubers (Fawke et al. 2015; Fry 2008; Kamoun et al. 2015; Nowicki et al. 2012). The resulting annual global harvest loss

P. Dahlin and M. C. Müller contributed equally to the work.

Corresponding authors: V. Bulone; E-mail: bulone@kth.se; and L. S. McKee; E-mail: mckee@kth.se

*The $\boldsymbol{e}$-Xtra logo stands for "electronic extra" and indicates that three supplementary figures and three supplementary tables are published online.

@ 2017 The American Phytopathological Society accounts for billions of dollars in potential revenue (Kamoun et al. 2015). Due to the resistant nature and hardy lifecycle of $P$. infestans, techniques such as crop rotation are of limited effect in controlling spread. The effectiveness of pesticides are limited by the development of fungicide resistance, the emergence of new strains (Ferreres et al. 2011; Fry 2008), and concerns for human health and environmental impact (Lamberth et al. 2013; Russell 2005). The control of potato late blight, therefore, remains a major challenge to agriculture (Axel et al. 2012; Kamoun et al. 2015). Mitigation strategies often center on secondary metabolite-based breeding programs aiming to increase plant resistance to infection.

The nightshade plants (family Solanaceae) produce a wide variety of nitrogen-containing secondary metabolites, known as alkaloids (Heretsch and Giannis 2015). These compounds are believed to have a major role in protection against infection or attack (Friedman 2002, 2004). They display antimicrobial properties (Cushnie et al. 2014; Heretsch and Giannis 2015) and many are toxic to animals (Fattorusso and Taglialatela-Scafati 2007; Lee 2007). The steroidal alkaloids (SAs) derive from sterols and may, in turn, be specifically glycosylated to the bittertasting steroidal glycoalkaloids (SGAs) (Fig. 1) (Fattorusso and Taglialatela-Scafati 2007). SGAs are particularly abundant in crop plants such as potatoes (Solanum tuberosum) and tomatoes (Solanum lycopersicum) (Friedman et al. 1997; Milner et al. 2011; Munafo and Gianfagna 2015; Petersson et al. 2013a). In these plants, the biosynthetic precursor of SGAs is cholesterol (Ohyama et al. 2013; Petersson et al. 2013b). In potato plants, cholesterol is cyclized into solanidine, which is subsequently glycosylated to $\alpha$-solanine or $\alpha$-chaconine (Fig. 1) (Caspi et al. 2014; Ginzberg et al. 2009; Krits et al. 2007; McCue et al. 2006, 2007; Moehs et al. 1997). These compounds represent up to $95 \%$ of the total SGAs in potato (Friedman et al. 1997; Milner et al. 2011). Light exposure, heat, wounding, or postharvest stress can significantly increase tuber SGA content (Petersson et al. 2013a), with associated increases in the risks to human health (Milner et al. 2011). Structurally similar SGAs are found in tomato and aubergine (Solanum melongena), with small but significant differences in the steroid or carbohydrate moieties, or both (Fig. 1) (Jiang et al. 2016; Milner et al. 2011).

A range of responses to SGAs and SAs have been described for various pests and pathogens (Byrne et al. 2001; Fewell and Roddick 1997; Milner et al. 2011; Nenaah 2010; Sanford et al. 1992). Growth inhibition has been reported for several fungal species and some bacteria (Fewell and Roddick 1997; Friedman 2002; Ito et al. 2007; Munafo and Gianfagna 2011; Sandrock 

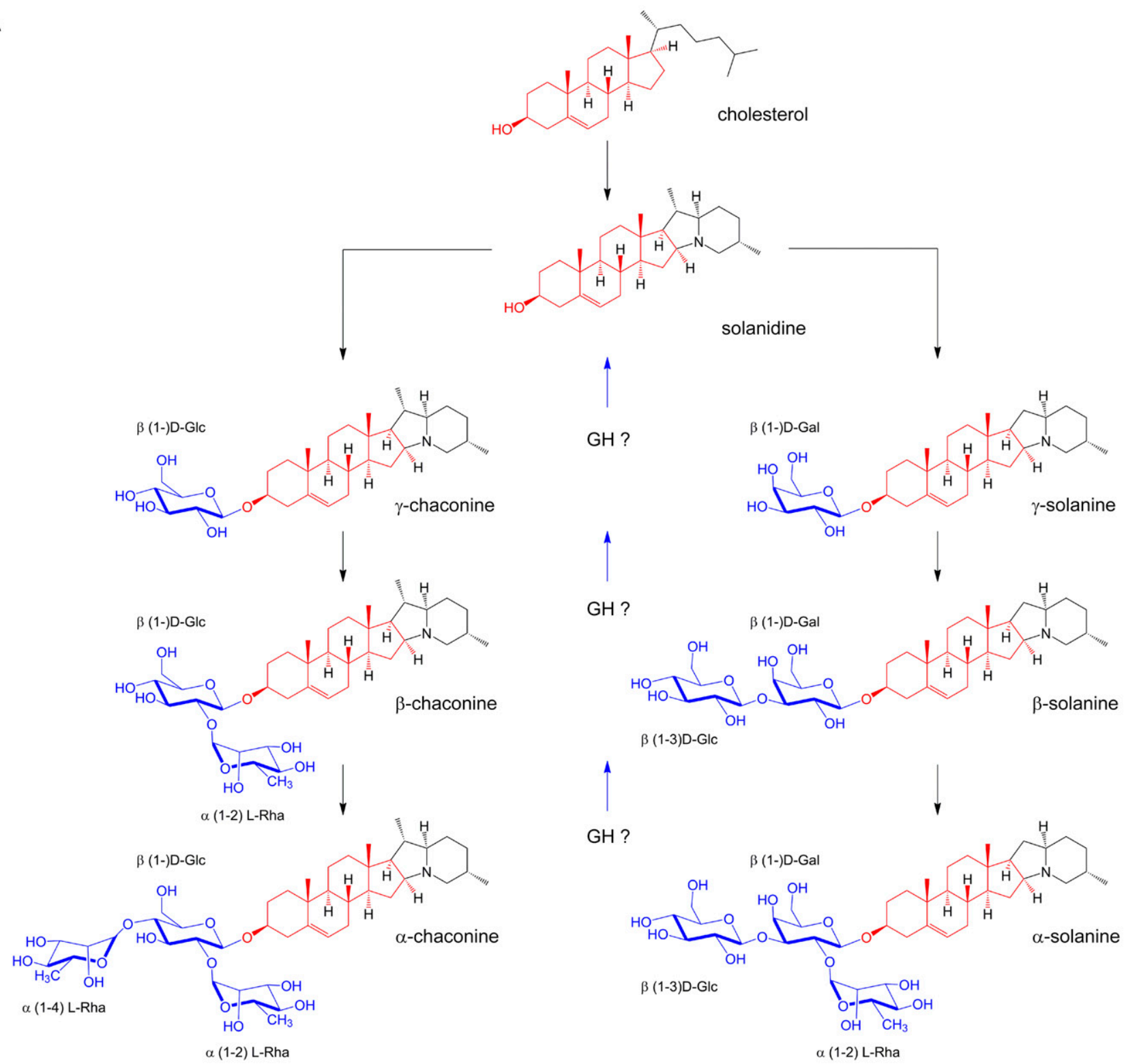

cholesterol

B
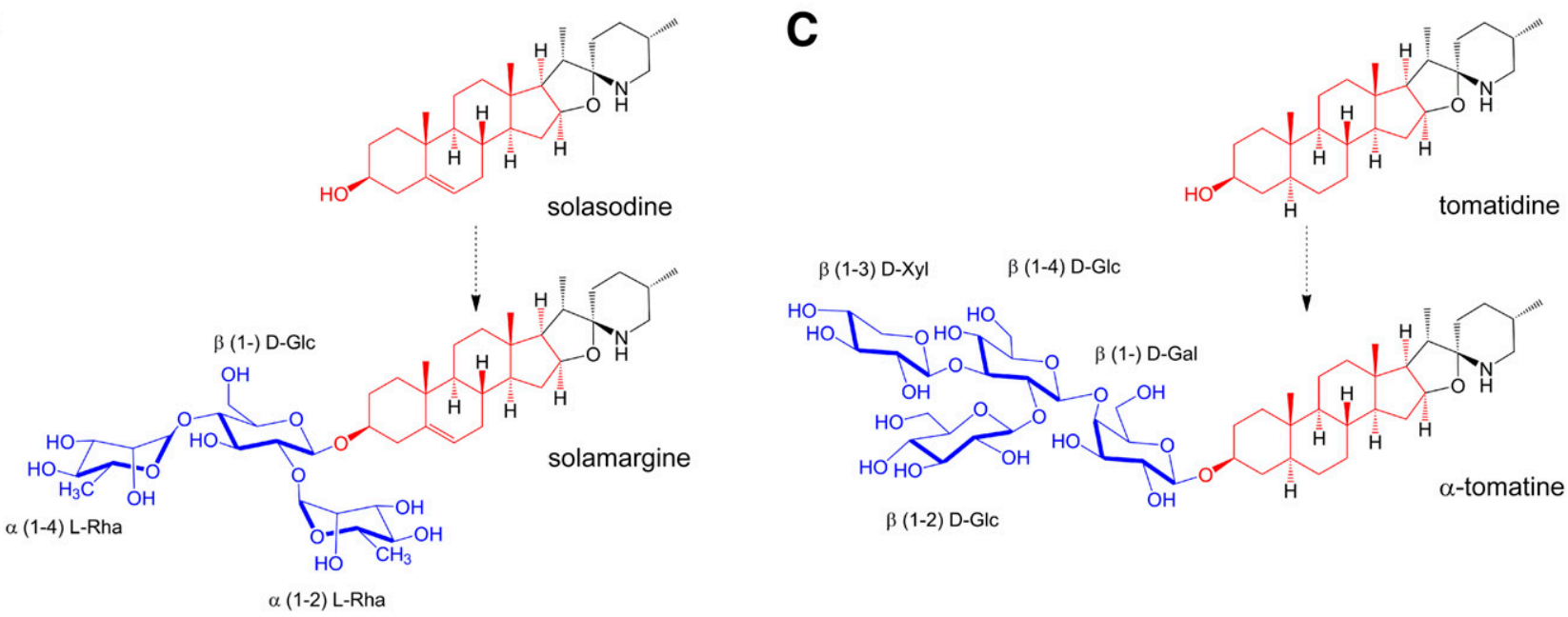

Fig. 1. Chemical structure and enzymatic modifications of steroidal alkaloids (SAs) and steroidal glycoalkaloids (SGAs). A, Biosynthetic pathway of the two main potato SGAs $\alpha$-solanine and $\alpha$-chaconine. Cholesterol is first cyclized to form the SA solanidine. Subsequent glycosylation steps lead to the production of either $\alpha$-chaconine or $\alpha$-solanine via multiple intermediates. The upward arrows indicate the potential de-glycosylating activities of unknown glycoside hydrolases (GHs). B, Structures of solasodine and the glycosylated solamargine, found in aubergine. C, Structures of tomatidine and the glycosylated $\alpha$-tomatine, found in tomato. 
and VanEtten 1998; Seipke and Loria 2008), but these results are often inconclusive and difficult to confirm under field conditions. Many studies on P. infestans have uncovered no correlation between potato SGA content and a plant's ability to resist infection (Andreu et al. 2001; Andrivon et al. 2003; Carlson-Nilsson et al. 2011; Deahl et al. 1973; Sarquís et al. 2000). There does appear to be a significant correlation between potato $\alpha$-chaconine content and the strength of the plant defense response in terms of lesion size but without any associated changes in mycelial growth rate (Carlson-Nilsson et al. 2011).

In humans and animals, the toxic effects of SGAs are attributed to direct inhibition of cholinesterase activity (Roddick 1989) and more general cell membrane disruption mediated via interactions between membrane sterols and the steroidal moiety of the SGA (Keukens et al. 1992, 1995, 1996; Roddick 1979; Roddick and Rijnenberg 1986). Additional interactions between membrane sterols and the glycan moiety of SGAs might lead to membrane budding and increased permeability, resulting in loss of ion conductivity of the cells (Augustin et al. 2011; Lin and Wang 2010; Manrique-Moreno et al. 2014). Because of this, the deglycosylation of SGAs has been suggested as a possible mechanism of detoxification in various microbes (Kaup et al. 2005; Martin-Hernandez et al. 2000; Ökmen et al. 2013; Pareja-Jaime et al. 2008; Seipke and Loria 2008). Certain pathogens of the tomato plant secrete enzymes that deglycosylate $\alpha$-tomatine to various extents, producing a less-toxic environment for their growth (Ökmen et al. 2013; Sandrock and VanEtten 1998, 2001).

All SGA-deglycosylating enzymes characterized so far are glycoside hydrolases (GHs) belonging to either family 13 (GH13) or family 10 (GH10) (Kaup et al. 2005; Lombard et al. 2014; Ökmen et al. 2013). No enzymes specifically targeting potato SGAs have yet been described, although the deglycosylation of $\alpha$-chaconine by cleavage of the $\alpha-1,4-\mathrm{L}-\mathrm{Rh}$ a residue (Fig. 1A) has been demonstrated in fungi (Oda et al. 2002). Some pests are also able to remove the $\alpha-1,2-\mathrm{L}-\mathrm{Rha}$ (Fig. 1A) (Bergeron et al. 1988; Weltring et al. 1997). It has also been suggested that a strain of $P$. infestans possesses some limited ability to deglycosylate $\alpha$-solanine into solanidine (Holland and Taylor 1979) (Fig. 1A).

Here, we present an assessment of the susceptibility of $P$. infestans T30-4 (potato isolate) to SGAs from potato, tomato, and aubergine plants. The $P$. infestans species is known to infect all of these, but this particular strain may be better adapted to potato (Oyarzun et al. 1998). We have investigated the possibility of deglycosylation of the potato SGAs $\alpha$-solanine and $\alpha$-chaconine by identifying $\mathrm{GHs}$ that may remove sugars from these compounds. We have studied growth and the life cycle of
$P$. infestans in the presence of these compounds, assessed uptake of the compounds, and assayed the GH activity of enzymes secreted during growth. We were able to show that, in fact, solanidine has a greater physiological impact than its glycosylated forms in inhibiting the mycelial growth of $P$. infestans in liquid culture. Additionally, tomato-derived SGAs appear to exert a greater toxic effect on this isolate than compounds derived from potato, implying some level of host adaptation. The glycosylated and nonglycosylated forms of the potato compounds were all taken up and retained by $P$. infestans mycelium, with no apparent deglycosylation there or in the growth medium. Our results shed light on the interactions between SGAs and $P$. infestans and may help to guide future strategies for $P$. infestans management.

\section{RESULTS}

\section{Toxicity of SAs and SGAs.}

We tested the inhibitory potential of two potato SGAs, $\alpha$-chaconine and $\alpha$-solanine, and their nonglycosylated precursor solanidine on the growth rate of $P$. infestans. This was performed by measuring hyphal growth in liquid cultures in the presence of these compounds (Fig. 2). The growth of treated mycelium was compared with that of a positive control grown in medium supplemented with $50 \mu \mathrm{M} \beta$-sitosterol and a negative control of unsupplemented medium lacking $\beta$-sitosterol. This control permitted only severely impaired growth. Initial screening experiments showed that increasing alkaloid content up to $200 \mu \mathrm{M}$ did not lead to any measurable differences in growth profiles compared with $50 \mu \mathrm{M}$ (Supplementary Table $\mathrm{S} 1$ shows an example of $\alpha$-chaconine experiments), which approximately reflects the range of typical SGA content in tubers (Milner et al. 2011; Petersson et al. 2013a).

In the presence of $\beta$-sitosterol $(50 \mu \mathrm{M})$, the addition of solanidine $(50 \mu \mathrm{M})$ successfully inhibited growth of the P. infestans mycelium down to the level of the sterol-free control (Fig. 2A). $\alpha$-Chaconine at the same concentration also inhibited mycelial growth but to a far lesser extent, and, in these conditions, the mycelium was able to grow to maximal expansion in the wells. In the presence of $\beta$-sitosterol, no effect was observed for the mycelium treated with $\alpha$-solanine.

To evaluate whether the observed growth inhibition from $\alpha$-solanine and $\alpha$-chaconine was due to direct toxicity to $P$. infestans or the consequence of complex formation and sequestration of $\beta$-sitosterol in the medium (Roddick 1979), growth analyses were repeated in sterol-free medium (Fig. 2B). P. infestans exhibited impaired growth under all sterol-free conditions. Neither $\alpha$ chaconine nor $\alpha$-solanine reduced growth below the level of
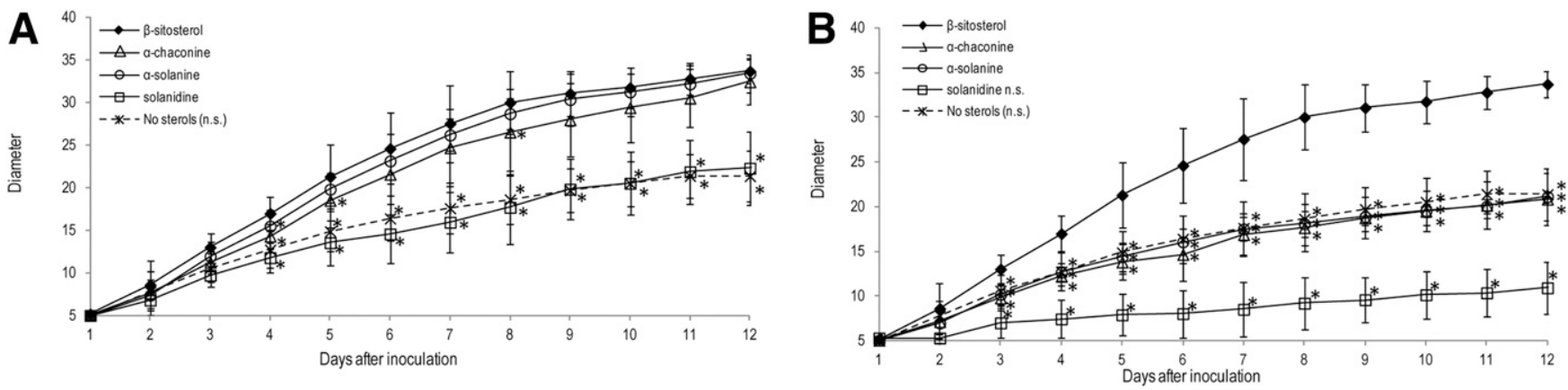

Fig. 2. Effects of potato-derived steroidal glycoalkaloids on Phytophthora infestans mycelial growth. Growth of $P$. infestans incubated with $\alpha$-chaconine, $\alpha$-solanine, or the nonglycosylated solanidine was measured as the diameter of hyphal expansion in the $\mathbf{A}$, presence or $\mathbf{B}$, absence of $\beta$-sitosterol. All compounds were included in growth medium at $50 \mu \mathrm{M}$. Data points represent an average of five biological replicates, each consisting of three to six technical replicates; error bars indicate standard deviation. Analysis of variance with Tukey's test of honest significant differences was performed using R, version 3.2.2. Asterisks indicate a significant difference compared with the $\beta$-sitosterol control. 
the sterol-free control, implying that the previously observed growth reduction with $\alpha$-chaconine (Fig. 2A) was due to a lack of available sterols in the medium. However, solanidine treatment was able to significantly reduce the growth of $P$. infestans beneath the level of the sterol-free control (Fig. 2B). This suggests that solanidine does exhibit direct toxicity on the organism. Light microscopy indicated that there was an increased accumulation of sporangia in some solanidine-treated wells compared with the control $\beta$-sitosterol samples (not shown). This increase in sporangia formation was not observed in wells containing either of the glycosylated SGAs.

\section{Mycelial uptake of potato-derived SAs and SGAs.}

To assess the ability of the $P$. infestans mycelium to take up the compounds under study, two different techniques of extraction for the SGAs $\alpha$-solanine and $\alpha$-chaconine and the SA solanidine were required (discussed below). High-performance thin-layer chromatography (HPTLC) analysis (Fig. 3) following extraction for SA/SGAs revealed that $\alpha$-solanine, $\alpha$-chaconine (Fig. 3A), and solanidine (Fig. 3B) were all taken up into the mycelium when present in the growth medium. There was hardly any detectable solanidine in the growth media after mycelium collection (Supplementary Fig. S1). Neither SGA appears to have been deglycosylated in the growth medium or in the mycelium, a structural change which would be reflected by a shift in mobility on the HPTLC plates to positions above the standards (Fig. 3B) (Filadelfi and Zitnak 1983).

Holland and Taylor (1979) suggested that $P$. infestans possesses very limited ability to deglycosylate $\alpha$-solanine into solanidine. As solanidine and $\beta$-sitosterol are difficult to distinguish by HPTLC (and are obtained together using the solanidine/sterol extraction procedure [Fig. 3B]), gas chromatography coupled to mass spectrometry (GC-MS) was utilized as a more sensitive analytical method to probe for solanidine in all mycelial samples (Fig. 4). The GC chromatograms and MS fragmentation patterns confirm that solanidine supplemented in the medium was taken up by $P$. infestans but was not present in mycelium grown in the presence of $\alpha$-solanine or $\alpha$-chaconine, again suggesting that these were not deglycosylated (Figs. 3B and 4). Equivalent analyses by GC-MS of the $\alpha$-solanine or $\alpha$-chaconine growth medium after collection of mycelial biomass could detect no solanidine, suggesting that the SGAs were also not deglycosylated in the extracellular environment (data not shown). Only traces of solanidine were detected in the growth medium supplemented with solanidine after $P$. infestans growth. There was efficient uptake of $\beta$-sitosterol in all samples (Fig. 4).

\section{Assessing the impact of nonpotato SGAs.}

To assess the specificity of the response to potato-derived compounds, growth of $P$. infestans was examined in the presence of SGAs derived from aubergine and tomato. These differ from the potato compounds in the sterol backbone or glycan chain (Fig. 1). These compounds all exhibit an inhibitory effect on the mycelial growth of the $P$. infestans strain studied here, regardless of whether sterols are also provided (Fig. 5). In the $50 \mu \mathrm{M}$ tomatidine concentration study, the $P$. infestans mycelium recovered within 12 days and reached a similar level of maximum growth as for the $\beta$-sitosterol control. The aubergine SA solasodine and SGA solamargine and the tomato SGA $\alpha$-tomatine have the tendency to inhibit $P$. infestans mycelial growth more strongly than the tomato SA tomatidine. The nonglycosylated tomatidine showed less toxicity than the glycosylated form
Steroidal glycoalkaloid extraction

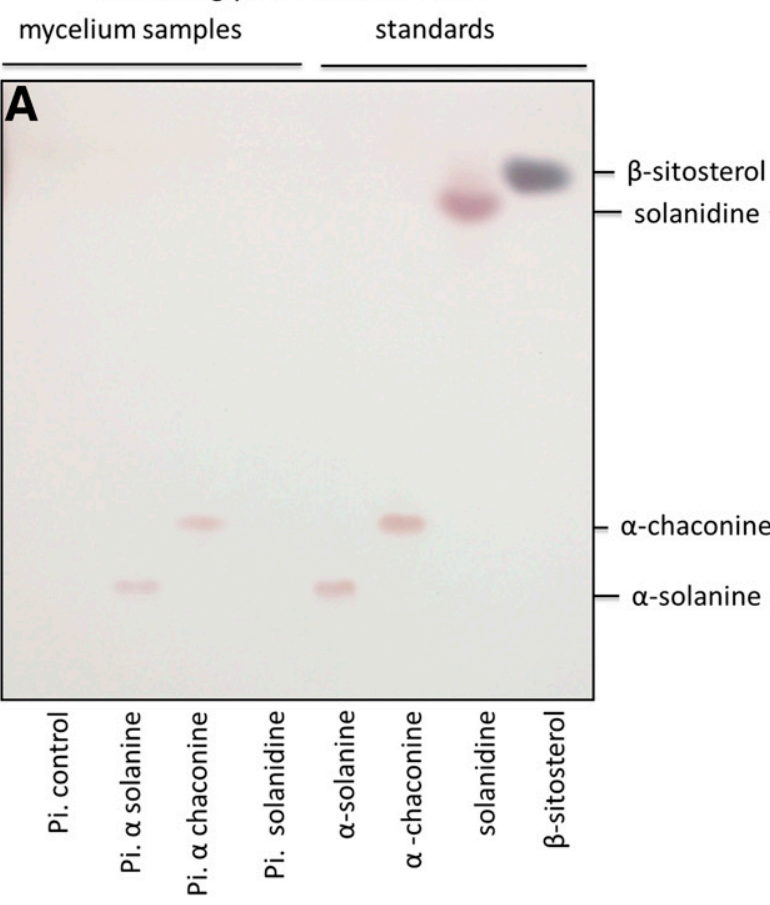

Steroidal alkaloid extraction

mycelium samples

standards

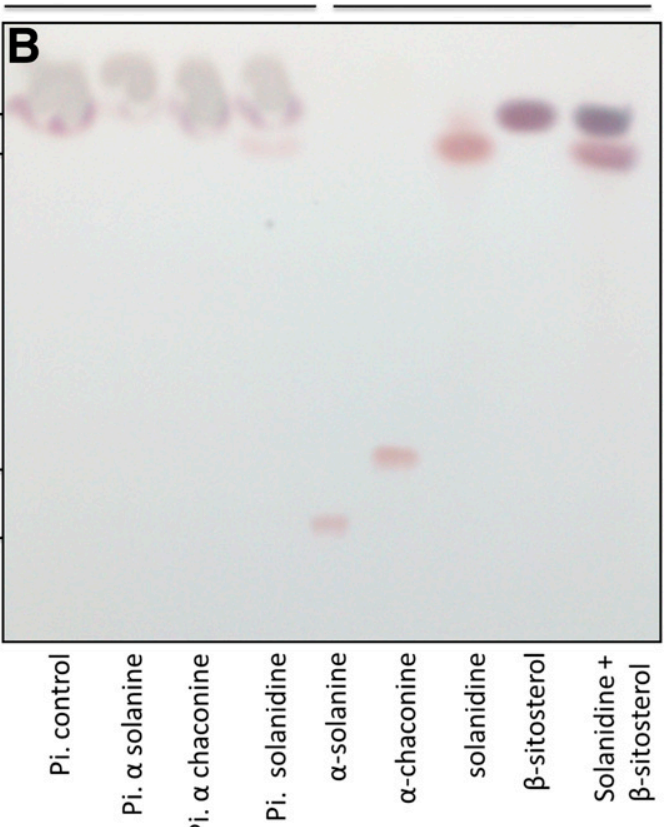

Fig. 3. Analysis of Phytophthora infestans mycelium for the presence of $\alpha$-solanine, $\alpha$-chaconine, and solanidine. A, Material extracted from P. infestans mycelium grown in the presence of $\alpha$-chaconine, $\alpha$-solanine, or solanidine, using the steroidal glycoalkaloid (SGA) extraction protocol, was analyzed by highperformance thin layer chromatography (HPTLC). Material extracted from P. infestans mycelium grown in the absence of SGAs and steroidal alkaloid (SA) was used as a negative control (Pi. control). Pure standards of $\alpha$-chaconine, $\alpha$-solanine, solanidine, and $\beta$-sitosterol were run to allow identification of spots. B, Material extracted from $P$. infestans mycelium grown in the presence of $\alpha$-chaconine, $\alpha$-solanine, or solanidine, using the solanidine/sterol extraction protocol, were analyzed by HPTLC to screen for the presence of solanidine. As for the SGA analyses, extracted material from $P$. infestans mycelium grown in the absence of SGAs and SA was used as a negative control (Pi. control). Pure standards of $\alpha$-chaconine, $\alpha$-solanine, solanidine, and $\beta$-sitosterol were run to allow identification of spots. 
$\alpha$-tomatine. This is an opposite trend than was observed for the potato-derived compounds.

\section{Identification of putative SGA deglycosylating enzymes.}

We utilized known fungal and bacterial tomatinase protein sequences (Supplementary Table S2) to identify potential SGAactive GHs in the predicted proteome of $P$. infestans. Using a protein sequence homology BLAST search, we identified four putative GH10 enzymes in the P. infestans proteome (Table 1) that have all previously been identified as GH10s (Brouwer et al. 2014; Lombard et al. 2014; Ospina-Giraldo et al. 2010). In addition, we identified a single putative SGA-active GH13 enzyme and six putative GH78 $\alpha$-L-rhamnosidases in the genome of $P$. infestans (Table 1). All previously described tomatinases are secreted proteins (Martin-Hernandez et al. 2000; Ökmen et al. 2013; Seipke and Loria 2008), providing motivation to predict the subcellular localization of the identified P. infestans proteins (Table 1). Three of the six GH78 genes, namely, PITG_05097,PITG_19230, PITG_19561, and two of the GH10s, PITG_17054 and PITG_17055, possess signal peptides for extracellular secretion (Table 1). Based on these criteria, we selected these five putative $P$. infestans GHs as the strongest candidate enzymes to remove the sugar moiety of potato SGAs.

Previously published microarray data show the expression of the selected genes in $P$. infestans during infection of potato leaves and when grown on various complex media (Haas et al. 2009). In this microarray study, all 11 genes listed in Table 1 were expressed, with the highest expression observed for PITG_04272 (GH10a) (Supplementary Fig. S2). None of the genes showed strong induction during infection of $P$. infestans on potato leaves as compared with when grown on other media. The highest induction was observed for PITG_05097 (pGH78a). A new quantitative polymerase chain reaction (qPCR) analysis of the five selected candidate genes was performed on RNA extracted from mycelium grown with sterols for 12 days in the presence of $\alpha$-solanine, $\alpha$-chaconine, or neither (Supplementary
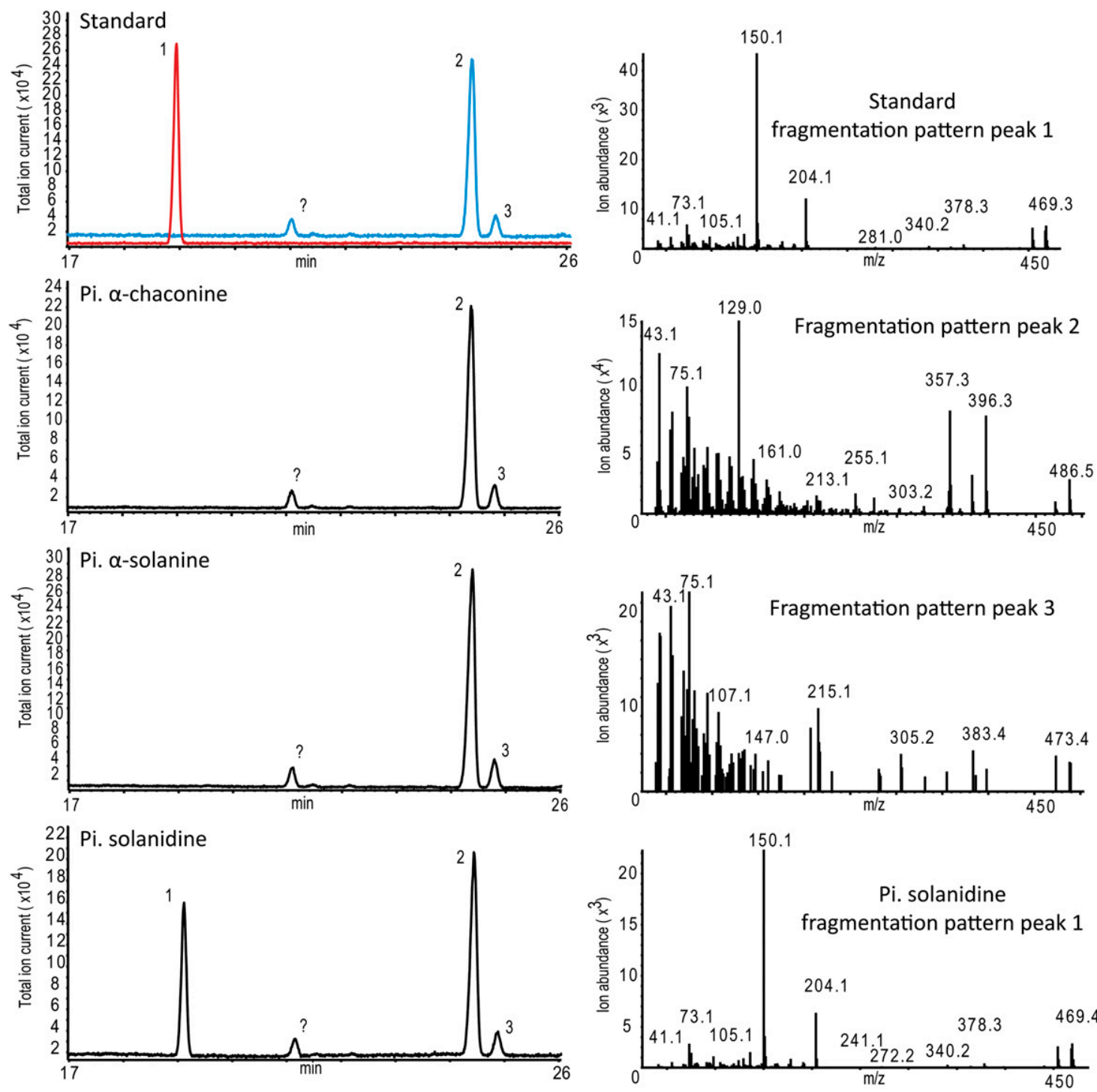

Fig. 4. Analysis by gas chromatography coupled to mass spectrometry (GC-MS) of sterols and steroidal alkaloid (SA) extracted from mycelium grown in different conditions. Materials extracted, using the solanidine/sterol extraction protocol, from Phytophthora infestans mycelium grown in the presence of the steroidal glycoalkaloids $\alpha$-chaconine and $\alpha$-solanine or the SA solanidine were analyzed by GC-MS to screen for the presence of solanidine. Peaks in GC chromatograms corresponding to solanidine and the sterols present in the growth medium are indicated: 1 , solanidine; 2 , $\beta$-sitosterol; and 3, campestanol (a minor contaminant of the commercial $\beta$-sitosterol). The question mark (?) indicates an unidentified compound present in the $\beta$-sitosterol supplemented to the culture medium. The mass spectrometry fragmentation peaks for these are also shown. The fragmentation pattern corresponding to peak 1 is shown for both the standard and sample runs. Fragmentation patterns for peaks 2 and 3 are shown for the standard run only. 
Fig. S3). Although there was a high degree of variability in gene expression between samples, no consistent significant changes in expression could be observed compared with the $\beta$-sitosterol control.

\section{Extracellular GH activity.}

In order to analyze the extracellular GH activity of $P$. infestans, we tested the ability of proteins secreted into the culture medium to cleave sugar residues from model chromogenic substrates and directly from SGAs. Secretomes produced during growth on $\beta$-sitosterol and those produced in the additional presence of $\alpha$-chaconine, $\alpha$-solanine, or solanidine were collected and tested for GH activity. In the aryl glycoside assay, all samples showed the highest activity for 4NP- $\beta$-Glcp, most likely induced by the sucrose present in the growth medium (Fig. 6A). Only very minor cleavage of $4 \mathrm{NP}-\alpha-\mathrm{Rhap}$ and $4 \mathrm{NP}$ $\beta$-Galp was observed (Fig. 6A). No significant differences in enzymatic activity could be observed between the secretome of the $\beta$-sitosterol control culture compared with samples treated with $\alpha$-chaconine or $\alpha$-solanine. Activity against $\alpha$-chaconine and $\alpha$-solanine was assessed by screening for the release of rhamnose, glucose and galactose by HPAEC-PAD (high performance anion exchange chromatography with pulsed amperometric detection). Minute amounts of monosaccharides were found in the SGA substrates, but there was no compelling evidence for rhamnose, galactose, or glucose release from either compound by any secretome tested (Fig. 6B).

\section{DISCUSSION}

Breeding strategies for resistance against late blight in potato have often attempted to increase the content of secondary metabolites such as nitrogen-containing alkaloids (Friedman 2002). These compounds have been linked to many types of plant defense against herbivores and pathogens (Friedman 2004; Milner et al. 2011), but, to our knowledge, no definitive investigation of the toxicity of SGAs to $P$. infestans has yet been presented. Our results, summarized in Figure 7, show that the potato-derived SGAs $\alpha$-chaconine and $\alpha$-solanine exert no significant direct inhibition of mycelial growth of $P$. infestans, while the nonglycosylated form solanidine has a strong inhibitory effect. Similar observations have been made for Saccharomyces cerevisiae and the fungal phytopathogen Alternaria solani (Simons et al. 2006, Sinden et al. 1973). Our results indicate that the detoxification of SGAs by enzymatic deglycosylation (Keukens et al. 1992) is not a universal mechanism, although it has been proposed for several species (Kaup et al. 2005; Martin-Hernandez et al. 2000; Ökmen et al. 2013; Pareja-Jaime et al. 2008; Seipke and Loria 2008).

SGA toxicity may be mediated via membrane disruption, the extent of which depends on the precise structure of the interacting SGA and membrane sterols. $\alpha$-Chaconine typically causes a higher degree of membrane disruption than $\alpha$-solanine, as it more readily complexes with sterols (Keukens et al. 1992). Our results

Table 1. Summary and properties of putative glycoside hydrolases identified in Phytophthora infestans ${ }^{\mathrm{a}}$

\begin{tabular}{lcccc}
\hline Gene ID & Identifier & $\begin{array}{c}\text { Protein } \\
\text { size (a.a.) }\end{array}$ & $\begin{array}{c}\text { Protein molecular } \\
\text { weight (kDa) }\end{array}$ & $\begin{array}{c}\text { Signal } \\
\text { peptide }\end{array}$ \\
\hline PITG_05097 & pGH78a & 653 & 70.4 & $\mathrm{~S}$ \\
PITG_19230 & pGH78b & 542 & 57.8 & $\mathrm{~S}$ \\
PITG_22085 & pGH78c & 442 & 48.0 & - \\
PITG_19561 & pGH78d & 779 & 84.8 & $\mathrm{~S}$ \\
PITG_01760 & pGH78e & 672 & 74.4 & - \\
PITG_01765 & pGH78f & 119 & 12.8 & - \\
PITG_04272 & pGH10a & 127 & 13.6 & - \\
PITG_04273 & pGH10b & 212 & 23.1 & - \\
PITG_17054 & pGH10c & 359 & 40.0 & $\mathrm{~S}$ \\
PITG_17055 & pGH10d & 384 & 42.7 & $\mathrm{~S}$ \\
PITG_05526 & pGH13 & 707 & 76.7 & - \\
\hline
\end{tabular}

a Genes highlighted in gray encode proteins with similarity to known steroidal glycoalkaloid-deglycosylating enzymes and are predicted to be secreted. The presence of a predicted signal peptide for protein secretion is indicated by an ' $S$ ' and the absence of a signal peptide is indicated by a dash $(-)$. a.a. $=$ amino acids.
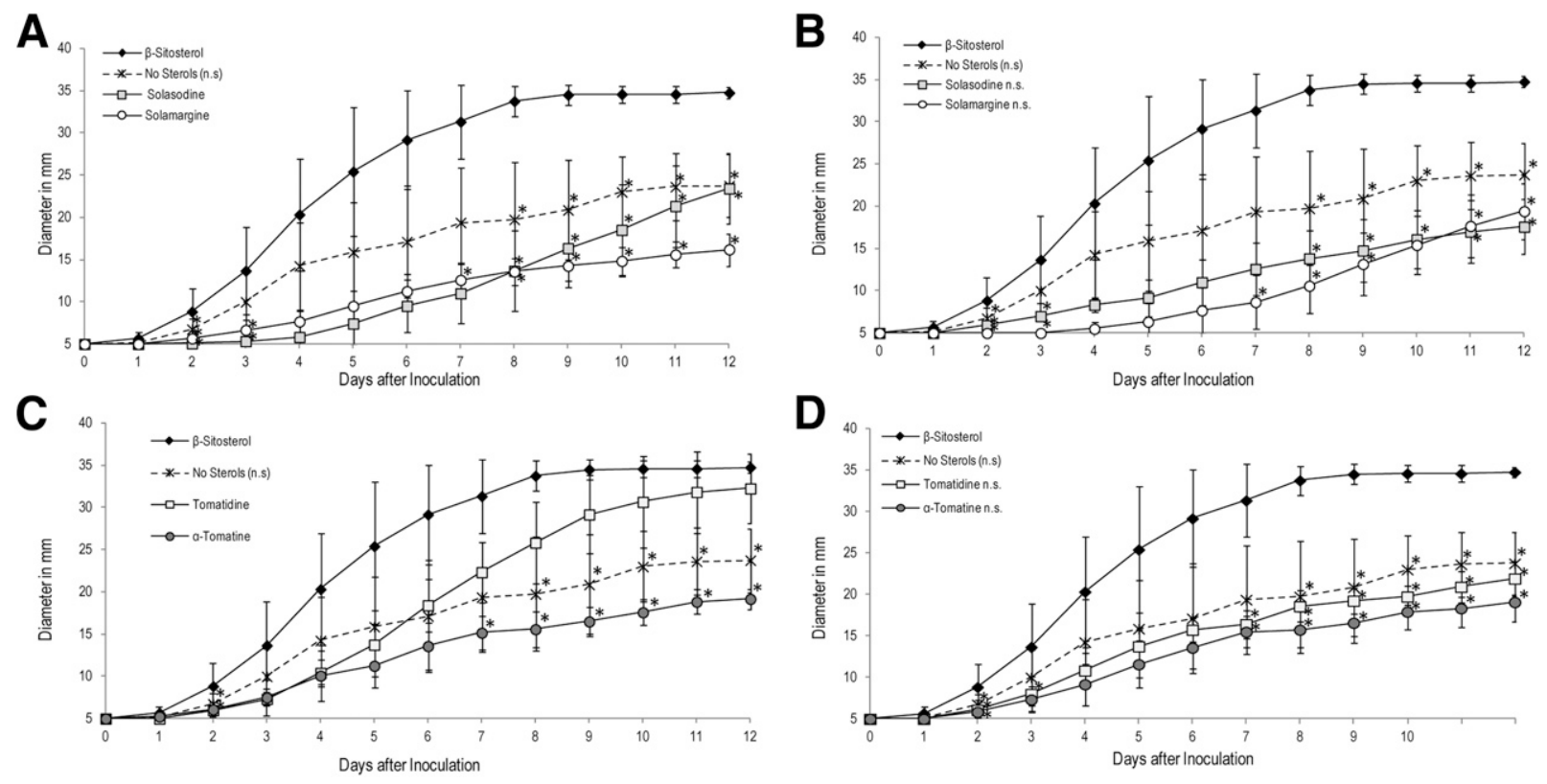

Fig. 5. Effects of nonpotato steroidal glycoalkaloids (SGAs) on Phytophthora infestans mycelial growth. Effect on growth of $P$. infestans was measured as diameter of hyphal expansion in the presence or absence of $\beta$-sitosterol. A, Aubergine steroidal alkaloid (SA) (solasodine) and SGA (solamargine) in the presence of $\beta$-sitosterol. B, Aubergine SA and SGA in the absence of $\beta$-sitosterol. C, Tomato SA (tomatidine) and SGA ( $\alpha$-tomatine) in the presence of $\beta$-sitosterol. D, Tomato SA and SGA in the absence of $\beta$-sitosterol. All compounds were included in the growth medium at $50 \mu \mathrm{M}$. Data points represent an average of six biological replicates; error bars indicate standard deviation. Analysis of variance analysis with Tukey's test of honest significant differences was performed using R, version 3.2.2. Asterisks indicate a significant difference compared with the $\beta$-sitosterol control. 
indicate that the minor inhibition of $P$. infestans growth caused by $\alpha$-chaconine (Fig. 2A), not observed in sterol-free conditions (Fig. $2 \mathrm{~B})$, is due to a nonspecific effect, likely SGA-sterol complex formation in the liquid medium reducing the availability of exogenous sterols, which are essential for growth of $P$. infestans (Roddick and Rijnenberg 1986).

Our data show that sterol uptake appears to be efficient in all conditions tested (Fig. 3). This process is likely mediated via sterol carrier proteins known as elicitins, which are believed to bind the C3 hydroxyl group of the sterols (Choi et al. 2010).The C3 hydroxyl group is important for membrane-associated activities (Friedman et al. 2005), and is also present in solanidine (Fig. 1A). A simplistic explanation for the observed differences in toxicity could be that elicitin-mediated uptake of solanidine is more likely than that of $\alpha$-chaconine or $\alpha$-solanine, which lack the C3 hydroxyl group (Fig. 1A). However, we were readily able to demonstrate that $P$. infestans is able to take up all potato compounds tested (Fig. 3). In contrast, a previous study on fungi showed that potato SGAs were not taken up (Fewell and Roddick 1997). Mechanisms for SA-related toxicity have been proposed in two
A

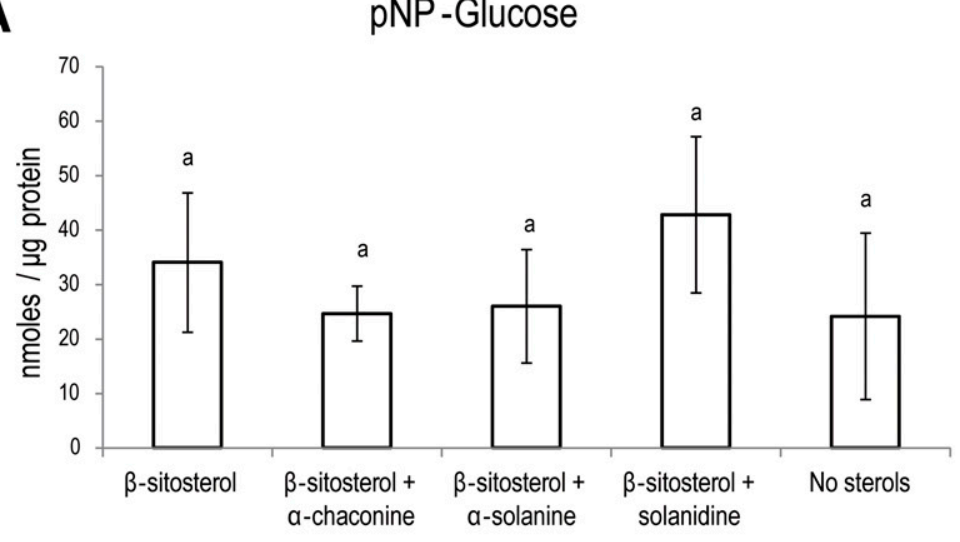

pNP-Galactose

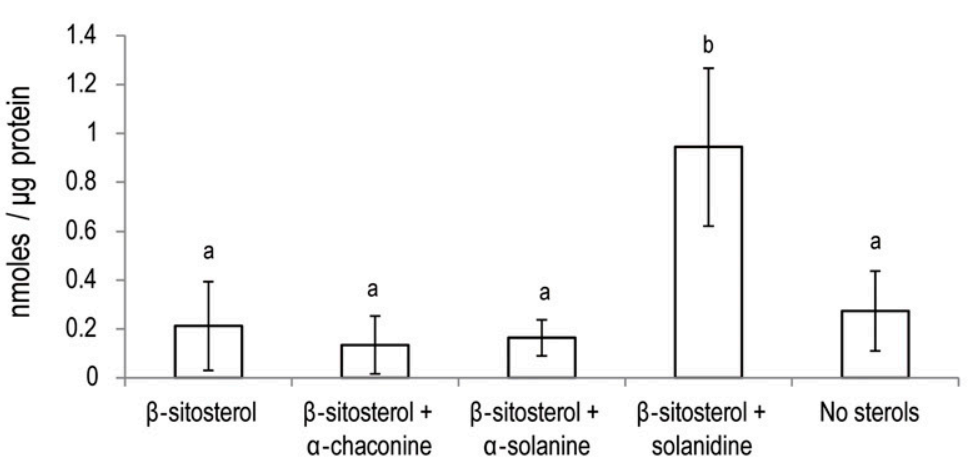

pNP-Rhamnose

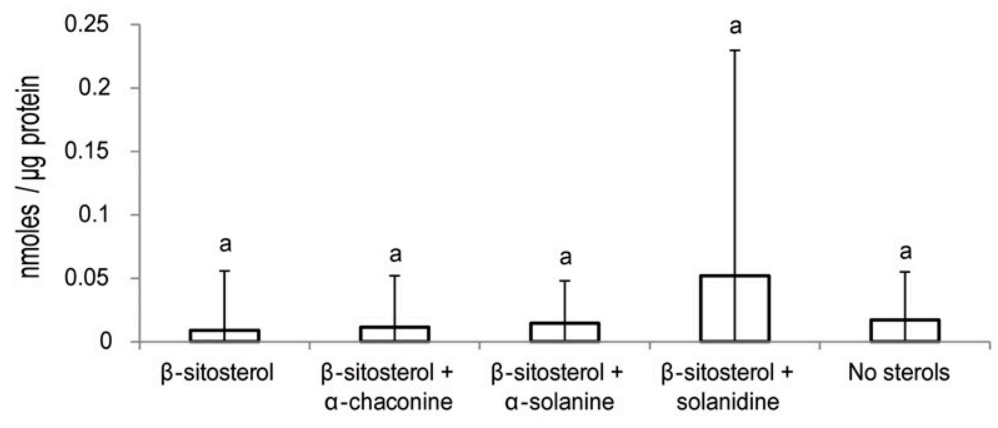

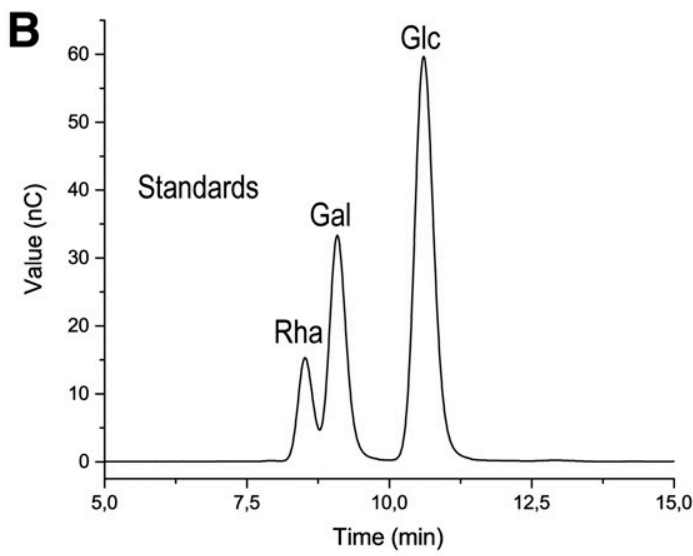
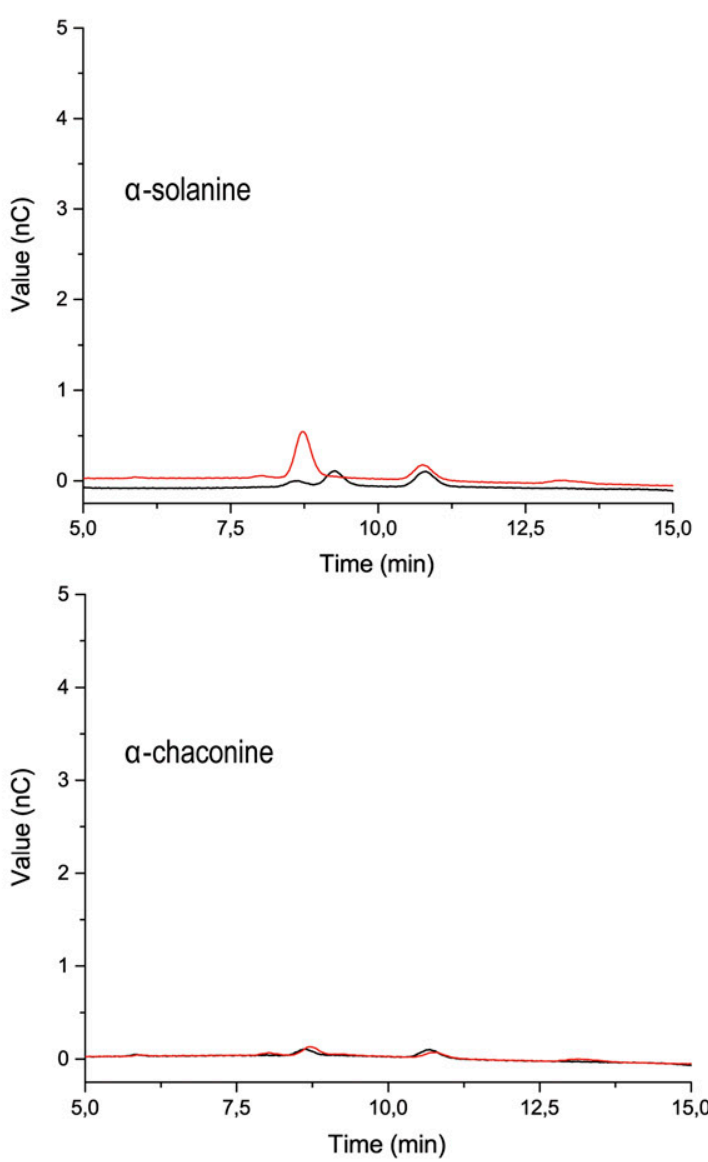

Fig. 6. Glycoside hydrolysis by proteins secreted by Phytophthora infestans during growth in liquid medium. A, Cleavage of three aryl glycosides serving as model substrates for the saccharide moieties of $\alpha$-chaconine and $\alpha$-solanine. Bars represent the average of six biological replicates (five for $\beta$-sitosterol + solanidine), error bars indicate standard deviation. Data were assessed for statistical significance by Tukeyhonest significant differences test $(P<0.001)$ : a, not significantly different from other samples; $b$, significantly different from other samples. Note that for the pNP-rhamnose assay of proteins collected following growth on solanidine, only one of six replicate samples showed activity, leading to a high standard deviation. B, Release of monosaccharides from steroidal glycoalkaloids analyzed by high performance anion exchange chromatography with pulsed amperometric detection. Black lines: time 0 control samples (substrate incubated with enzyme predenatured by boiling for $10 \mathrm{~min}$ ); red lines: samples after $14 \mathrm{~h}$ incubation. The standards shown are each at a concentration of $0.1 \mathrm{~g}$ per liter. Note the difference in magnitudes on the $y$ axis scales for the standard and sample chromatograms. 
recent studies describing the effects of tomato-derived tomatidine. These suggest that toxicity was not associated with membrane disruption but was due to alterations of lipid metabolism, particularly sterol metabolism (Medina et al. 2015; Simons et al. 2006). The same has been reported for solanidine toxicity in yeast (Simons et al. 2006). It will be of interest to see whether this effect is a general mechanism in all oomycetes or if there are different responses in sterol-synthesizing species. Nonetheless, we have shown that SA toxicity is a specific metabolic effect, rather than a result of extracellular interactions that reduce sterol uptake.

One of the features underlying the success of $P$. infestans is the ability to survive for long durations by forming thick-walled oospores, which allow survival through winters and crop rotations, or thin-walled sporangia, adapted for efficient spread by wind transport (Judelson and Blanco 2005). Visual observation of liquid medium in growth wells indicated that there was an elevated accumulation of sporangia in some solanidine-treated wells. This underscores our observation that SA toxicity affects the physiology of the organism. This defensive response could be the outcome of a specific adaptation to solanidine, in which sporulation is the first step in moving to a new host plant. However, other sources of stress, such as nutrient depletion and aging, have also been associated with increased sporangia formation and a generalized stress response to our experiments is plausible (Kim and Judelson 2003).

Pest and pathogen adaptation to specific SGAs has previously been proposed, such as in fungal tomato pathogens that display higher tolerance toward the tomato SGA $\alpha$-tomatine than do species that are not tomato pathogens (Milner et al. 2011; Sandrock and VanEtten 1998). Host specificity has also been described for $P$. infestans in terms of survival and virulence (Oyarzun et al. 1998). This is also echoed in our observations, as SGAs naturally found in tomato and aubergine plants showed greater toxicity to $P$. infestans T30-4 (initially isolated from potato) than the potato-derived $\alpha$-chaconine and $\alpha$-solanine (Fig. 7). This apparent adaptation to typical hostplant SGAs may hint at a possible mechanism of toxicity; $\alpha$-solamargine possesses the same sugar moiety as $\alpha$-chaconine but exerts a greater inhibitory effect on $P$. infestans growth than $\alpha$-chaconine, which has a different steroidal backbone structure

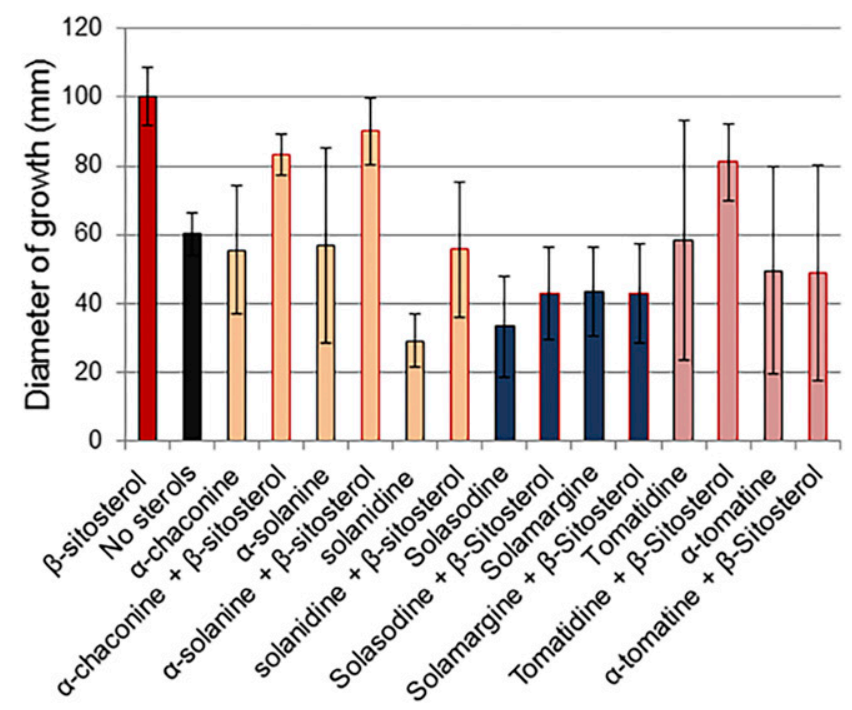

Fig. 7. Summary of the effects of steroidal glycoalkaloid (SGA) and steroidal alkaloid (SA) treatment on Phytophthora infestans mycelium after 8 days of growth. Medium containing $\beta$-sitosterol and no added SA or SGA compound served as the basic growth medium and as the positive control. The negative control was medium lacking any supplemented sterols. The extent of growth is shown as the diameter of the mycelial colonies in micrometers.
(Fig. 1), implying a role for the steroidal moiety in SGA toxicity.

The deglycosylation of SGAs by GHs as a means of possible detoxification has been considered in several studies (Ökmen et al. 2013; Pareja-Jaime et al. 2008), although our data suggest that deglycosylation of $\alpha$-chaconine or $\alpha$-solanine to solanidine would, in fact, increase toxicity to $P$. infestans. Prominent examples of SGA-deglycosylating GHs are the GH10 tomatinases, which cleave the tetrasaccharide lycotetraose from $\alpha$-tomatine (Ökmen et al. 2013) (Fig. 1). $\alpha$-Solanine contains the same glycan and has been reported to be deglycosylated to solanidine by $P$. infestans (Holland and Taylor 1979). Cleavage of the terminal rhamnose of $\alpha$-chaconine has also been described in various fungal strains (Oda et al. 2002), and a GH13 $\alpha$-Lrhamnosidase has been shown to act on glycosylated plant compounds (Feng et al. 2007; Liu et al. 2012; Yadav et al. 2010). Several candidate GHs were identified with putative SGA activity (Table 1), and all genes encoding these enzymes were expressed under all conditions tested. However, there was no significant induction of gene expression by SGAs nor was there any hydrolysis of SGAs or their component sugars by proteins secreted during growth in the presence of the compounds (Fig. 6). Nor was there any evidence of deglycosylation of the compounds in the mycelium (Fig. 3). It is therefore to be assumed that $P$. infestans has alternative mechanisms to cope with the membrane disrupting properties of SGAs. The ability to tolerate potato SGAs may even confer a survival advantage over other pathogens or strains not specifically adapted to the host plant (Oyarzun et al. 1998), contributing to the global success of $P$. infestans.

In addition to being a potential inhibitor of $P$. infestans growth, high levels of the SA solanidine may also be toxic to the plant (Itkin et al. 2011; Ökmen et al. 2013). The importance of the glycosylation of tomatidine to $\alpha$-tomatine in tomato plants has been demonstrated in gene-silenced plants with excessive accumulation of tomatidine, which show growth reduction and morphological aberrations (Itkin et al. 2011). Potatoes typically contain only trace amounts of solanidine (Friedman et al. 1997), suggesting that glycosylation to SGAs proceeds very rapidly, with almost no accumulation of the SA intermediate. This indicates that solanidine accumulation might be similarly harmful to the potato plant, ruling out this secondary metabolite as a candidate for enrichment by targeted breeding approaches. High levels of solanidine may also be toxic to humans (Milner et al. 2011; Roddick 1989). Solanidine is a very minor component in edible potatoes but is readily detectable in the bloodstreams of people who eat potatoes, implying SGA deglycosylation in humans (Claringbold et al. 1982; Friedman et al. 1997; Harvey et al. 1985; Hellenäs et al. 1992). There is evidence that SAs do inhibit cholinesterase activity, though often to a lesser extent than their glycosylated counterparts (Harris and Whittaker 1962; Roddick 1989).

In humans, excessive consumption of SGAs causes symptoms in both the gastrointestinal tract and the nervous system (Ginzberg et al. 2009). Due to this toxicity, SGA and SA levels are a major concern in today's potato breeding programs. Historical surveys have shown that most natural variants have SGA contents in mature tubers of 20 to $100 \mathrm{mg}$ per kilogram of fresh weight, with some possessing many times this level (Sinden and Webb 1974). Early attempts to breed potato plants with increased pest resistance (Akeley et al. 1968; Friedman et al. 1997) led to the Lenape variety, which was unfit for human consumption due to a glycoalkaloid concentration of 200 to $300 \mathrm{mg} / \mathrm{kg}$ (Mensinga et al. 2005; Zitnak and Johnston 1970). The SGA content in potato tubers is now subject to strict regulation and may not exceed $200 \mathrm{mg}$ per kilogram of fresh weight (Korpan et al. 2004). This and environmentally-induced variability in SGA 
content limit the options available to breeders who might wish for variants with higher SGA contents to counter certain pests (Petersson et al. 2013a; Hellenäs et al. 1995; Sinden and Webb 1974). However, as we have shown that $P$. infestans T30-4 is tolerant to potato SGAs, the enrichment of these compounds by breeding programs would not in any case be an effective pest management strategy. The effects described here should still be confirmed in planta, as many unanswered questions remain regarding the interactions between plants and oomycetes and the mechanism of infection.

\section{MATERIALS AND METHODS}

\section{Assessment of $P$. infestans growth.}

The mycelium of $P$. infestans T30-4 was cultivated at $25^{\circ} \mathrm{C}$ in darkness in petri dishes containing $2 \%$ agar supplemented with (per liter) $1.9 \mathrm{~g}$ of $\mathrm{KH}_{2} \mathrm{PO}_{4}, 1.04 \mathrm{~g}$ of $\mathrm{K}_{2} \mathrm{HPO}_{4}, 0.2 \mathrm{~g}$ of $\mathrm{MgSO}_{4} \cdot 7 \mathrm{H}_{2} \mathrm{O}, 15 \mathrm{~g}$ of sucrose, $2 \mathrm{~g}$ of L-asparagine, $10 \mathrm{mg}$ of $\mathrm{CaCl}_{2} \cdot \mathrm{H}_{2} \mathrm{O}, 1 \mathrm{mg}$ of $\mathrm{ZnSO}_{4} \cdot 7 \mathrm{H}_{2} \mathrm{O}$, and $1 \mathrm{mg}$ of thiamine- $\mathrm{HCl}$, and $50 \mu \mathrm{M} \beta$-sitosterol (Sigma Aldrich, St. Louis). Plates were incubated at $25^{\circ} \mathrm{C}$ in darkness. For the growth study in the presence of $\beta$-sitosterol, SAs, and SGAs, agar plugs $5 \mathrm{~mm}$ in diameter were excised with a cork borer from one-week-old solid plates containing $P$. infestans mycelium. The agar was removed prior to inoculation of the mycelium into liquid medium of the same composition as above, except for the addition of $50 \mu \mathrm{M}$ of either solanidine, $\alpha$-solanine, $\alpha$-chaconine, tomatidine, or $\alpha$-tomatine from Extrasynthese (Genay, France) or $50 \mu \mathrm{M}$ of solasodine or $\alpha$-solamargine from Glycomix (Reading, U.K.). Each experiment was performed in the presence or absence of $50 \mu \mathrm{M} \beta$-sitosterol. Growth was monitored by measuring the diameter of the mycelium over 2 weeks of culture at $25^{\circ} \mathrm{C}$ in darkness. Mycelial diameter was measured by visualizing wells placed onto a surface marked with a millimeter-scale grid. For subsequent experiments, the mycelium was harvested and was washed with water and quickly dried with filter paper before being frozen in liquid $\mathrm{N}_{2}$ and stored at $-80^{\circ} \mathrm{C}$.

\section{Extraction of solanidine, SGAs, and sterols.}

SGAs were recovered from the mycelium as previously described (Petersson et al. 2013b). Approximately $0.5 \mathrm{~g}$ of frozen mycelium was ground to powder in liquid $\mathrm{N}_{2}$ and was transferred to a $15-\mathrm{ml}$ plastic tube. Five milliliters of $5 \%$ acetic acid in water was added and the mixture was sonicated for $15 \mathrm{~min}$ in a water bath. The soluble extract was isolated by centrifugation for $20 \mathrm{~min}$ at $4,500 \times g$, and the supernatant was further processed by solid-phase extraction (SPE) using SPE columns (Isolute C18 phase, $500 \mathrm{mg} / 3 \mathrm{ml}$; Biotage, Uppsala, Sweden). One column per sample was activated by the adding $5 \mathrm{ml}$ of acetonitrile and preconditioning with $5 \mathrm{ml}$ of $5 \%$ acetic acid in water prior to sample loading. Contaminants were removed by washing with $4 \mathrm{ml}$ of $15 \%$ acetonitrile. SGAs were then eluted in $50 \%$ acetonitrile and were dried and solubilized in $500 \mu \mathrm{l}$ $50 \%$ acetonitrile.

Solanidine and sterols were extracted from mycelium powdered in liquid $\mathrm{N}_{2}$, as above, except with chloroform/methanol (1:2) as a solvent. The internal standard betulin $(50 \mu \mathrm{l})\left(1 \mathrm{mg} \mathrm{ml}^{-1}\right.$ stock solution; Sigma-Aldrich) was added and the samples were vortexed vigorously. After $20 \mathrm{~min}$ of incubation at $60^{\circ} \mathrm{C}$, the samples were centrifuged at $450 \times g$ for $10 \mathrm{~min}$ to pellet insoluble material. The supernatant was transferred to a new glass tube and $3 \mathrm{ml}$ of chloroform/methanol (1:2) was added for a second extraction, collecting the supernatant liquid again. Both supernatants were pooled, and $2.5 \mathrm{ml}$ of chloroform and $2.5 \mathrm{ml}$ of $\mathrm{H}_{2} \mathrm{O}$ was added to the mixture, followed by vortexing and centrifugation for $10 \mathrm{~min}$ at $450 \times g$. The lower organic phase, containing solanidine and lipids, was recovered using Pasteur pipettes. The solvent was evaporated in $\mathrm{N}_{2}$ gas and the resulting dry compounds were resuspended in $3 \mathrm{ml}$ of hexane for SPE. Each SPE column (Isolute SI phase, $500 \mathrm{mg} / 6 \mathrm{ml}$; Biotage) was activated by the addition of $3 \mathrm{ml}$ of hexane. After sample loading, the columns were washed with $9 \mathrm{ml}$ of hexane to remove residues. Solanidine and sterols were eluted in $3 \mathrm{ml}$ of hexane/ethyl acetate (1:1) and all samples were dried under $\mathrm{N}_{2}$ gas until analysis.

To isolate SGAs from liquid medium, one volume of $10 \%$ acetic acid was added to one volume of sample. The mixtures were then sonicated for $15 \mathrm{~min}$ and centrifuged for $20 \mathrm{~min}$ at $4,500 \times g$. The supernatant was further processed by SPE as described above.

\section{Solanidine and SGA analysis by HPTLC.}

For HPTLC separation, dried SGAs and solanidine were dissolved in chloroform, were spotted directly onto HPTLC silica plates $\left(60 \mathrm{G} \mathrm{F}_{254}, 10 \times 10 \mathrm{~cm}\right.$ glass plates; Camag, Muttenz, Switzerland), and were run in a horizontal developing chamber (Camag), using a mobile phase of chloroform $/$ methanol $/ 2 \%$ aqueous $\mathrm{NH}_{4} \mathrm{OH}$ at a ratio of 70:30:5 (Simonovska and Vovk $2000)$. Commercial $\alpha$-solanine, $\alpha$-chaconine, solanidine, and $\beta$-sitosterol were used as standards. HPTLC plates were then immersed in $10 \%$ (wt/vol) $\mathrm{CuSO}_{4}$ and $8 \%$ (vol/vol) $\mathrm{H}_{3} \mathrm{PO}_{4}$ and were briefly heated at $150^{\circ} \mathrm{C}$, to detect the separated compounds.

\section{Solanidine and sterol analysis by GC-MS.}

Prior to GC-MS analysis, solanidine and sterols were silylated for $1 \mathrm{~h}$ at $60^{\circ} \mathrm{C}$ in the presence of $100 \mu \mathrm{l}$ of pyridine and $100 \mu \mathrm{l}$ of $\mathrm{N}, O$-bis(trimethylsilyl)trifluoroacetamide (BSTFA) with $1 \%$ trimethylchlorosilane (TMCS) (Sigma-Aldrich). Samples were then dried under $\mathrm{N}_{2}$ gas and were redissolved in 20 to $50 \mu \mathrm{l}$ of chloroform for GC-MS analysis. Analyses were performed on an HP 6890 series GC system fitted with an HP 5973 mass selective detector, using a CP-Sil 5 CB column $(30 \mathrm{~m} \times 0.25 \mathrm{~mm}$; Agilent Technologies Sweden AB, Kista, Sweden). Depending on the amount of the initial material, either 2 or $3 \mu$ of sample was injected. The injector with the transfer liner was set to $325^{\circ} \mathrm{C}$ and the oven with the column was set to $245^{\circ} \mathrm{C}$, with the first ramp going to $265^{\circ} \mathrm{C}$ with an increase of $3.5^{\circ} \mathrm{C}$ per min and the second ramp to $310^{\circ} \mathrm{C}$ by $0.5^{\circ} \mathrm{C}$ per min. Helium was used as the carrier gas. Commercial solanidine and $\beta$-sitosterol were used as standards to confirm the identity of each peak in the samples. Peak identity was further confirmed by comparison with GC-MS data from the online AOCS Lipid Library.

\section{Identification, expression analysis, and assay of GHs with potential activity on SGAs.}

Putative homologous proteins of GH10 tomatinases and GH13 and GH78 $\alpha$-L-rhamnosidases were identified in the $P$. infestans predicted proteome by BLASTp search. Expression microarray data for the identified $P$. infestans genes were obtained from a previously published study (Haas et al. 2009). Signal peptides and subcellular localization were predicted using Blast2GO and SignalP (Götz et al. 2011; Petersen et al. 2011).

For reverse transcription (RT)-qPCR expression analysis of $\mathrm{GH}$ genes, frozen $P$. infestans mycelium $\left(-80^{\circ} \mathrm{C}\right)$ was ground to powder in liquid $\mathrm{N}_{2}$, using a pestle and mortar. RNA extraction was performed using the RNeasy plant mini kit (Qiagen $A B$, Sollentuna, Sweden), following the manufacturer's instructions, except for an additional spin step of $10,000 \times \mathrm{g}$ for $2 \mathrm{~min}$ before the ethanol wash. To remove contaminating DNA, the eluted RNA was treated with the TURBO DNA-free kit (Ambion, from Thermo Fisher Scientific, Stockholm, Sweden), following the manufacturer's instructions. Total RNA concentration was measured using a NanoDrop (Thermo Fisher Scientific) and 
was qualitatively analyzed on a $1 \%$ agarose gel. A total of $3 \mu \mathrm{g}$ of RNA template was used for cDNA synthesis with the Maxima First Strand cDNA synthesis kit for RT-qPCR (Life Technologies, Stockholm, Sweden). For RT-qPCR, the reaction mixture comprised $0.5 \mu \mathrm{l}$ of $10 \mu \mathrm{M}$ primer, $1 \mu \mathrm{l}$ of cDNA template (stock concentration of $1.5 \mathrm{ng} \mathrm{\mu l}^{-1}$ ), $3.5 \mu \mathrm{l}$ of $\mathrm{H}_{2} \mathrm{O}$, and $5 \mu$ of SyberGreen supermix (BioRad, Hercules, CA, U.S.A.). Binding efficiency of the primers was estimated using the Realtime PCR Miner software (Zhao and Fernald 2005). RT-qPCR was performed using a $\mathrm{C} 1000$ thermal cycler (BioRad) and the following steps: $95^{\circ} \mathrm{C}$ for $3 \mathrm{~min}, 44$ cycles at $95^{\circ} \mathrm{C}$ for $10 \mathrm{~s}$, $59^{\circ} \mathrm{C}$ for $30 \mathrm{~s}, 72^{\circ} \mathrm{C}$ for $10 \mathrm{~s}$, and reaction termination at $95^{\circ} \mathrm{C}$ for $10 \mathrm{~s}$. Primer sequences of reference genes, i.e., TubB, $U b c E 2$, $P I T G$, and the target genes $p G H 78-a, p G H 78-b, p G H 78-d$, $p G H 10-c$, and $p G H 10-d$ are listed in Supplementary Table S3. Transcript abundance data were analyzed using a one-way analysis of variance (ANOVA) followed by a Tukey honest significant differences (HSD) test for pair-wise comparison in the R software (R Core Team 2012).

GH activity assays were performed on secreted proteins collected from independent liquid cultures of $P$. infestans harvested on different days. Proteins from a total of six replicate samples were used for the assays. The culture medium was first centrifuged to remove sporangia and incubated with and without the various glycoalkaloids under study. The proteins were concentrated using Amicon Ultra 0.5-ml centrifugal filter tubes with a molecular mass cut-off of $30 \mathrm{kDa}$ (Merk-Millipore, Cork, Ireland), and protein concentration was measured using the Bradford protein assay (Bradford 1976).

Aryl-glycoside reaction mixtures consisted of $50 \mathrm{mM}$ sodium phosphate buffer, $\mathrm{pH} 6.5,1 \mathrm{mM}$ substrate (4-nitrophenyl- $\beta$-DGlcp, 4-nitrophenyl- $\beta$-D-Galp, or 4-nitrophenyl- $\alpha-\mathrm{L}-\mathrm{Rhap}$ ), and protein (between 6.7 and $0.2 \mu \mathrm{g}$ of total protein) in $\mathrm{H}_{2} \mathrm{O}$ in a total reaction volume of $500 \mu \mathrm{l}$. Tubes were incubated overnight (approximately $14 \mathrm{~h}$ ) at room temperature with agitation (rotary shaking at $180 \mathrm{rpm}$ ). Reactions were stopped by the addition of an equal volume of $\mathrm{Na}_{2} \mathrm{CO}_{3}$ at $0.2 \mathrm{M}$ stock concentration. Substrate cleavage was quantified by measuring absorbance at $410 \mathrm{~nm}$ in a Cary 50 UV/Vis spectrophotometer (Varian; Agilent Technologies, Palo Alto, CA, U.S.A.). Data were analyzed using a one-way ANOVA followed by Tukey HSD for pair-wise comparison in the $\mathrm{R}$ software ( $\mathrm{R}$ Core Team 2012). Reactions lacking any protein were used as control.

For activity assays on SGAs, aliquots of $5 \mu \mathrm{l}$ of $\alpha$-chaconine and $\alpha$-solanine $(1 \mathrm{mM})$ dissolved in chloroform were evaporated and rediluted in $10 \mu \mathrm{l}$ of sodium phosphate buffer $(500 \mathrm{mM}, \mathrm{pH} 6.5)$ to a final SGA concentration of $830 \mu \mathrm{M}$. Secretome $(20 \mu \mathrm{l})$ was added to a final protein concentration of 0.86 to $2.1 \mu \mathrm{l}^{-1}$. A $10-\mu \mathrm{l}$ aliquot of each reaction was inactivated at $95^{\circ} \mathrm{C}$ for 2 min to serve as a time zero control for each sample. The remaining solution was incubated overnight (approximately $14 \mathrm{~h}$ ) at room temperature with agitation (rotary shaking at $180 \mathrm{rpm}$ ), after which, the reaction was stopped by heating at $95^{\circ} \mathrm{C}$ for $5 \mathrm{~min}$. Samples were stored at $4^{\circ} \mathrm{C}$ overnight, prior to analysis on a Dionex ICS-3000 HPAEC-PAD system using the Chromeleon software v6.80 (Dionex, Thermo Fisher Scientific) and a Dionex Carbopac PA1 column. Solvent A was water, solvent B was $1 \mathrm{M}$ sodium hydroxide, and solvent $\mathrm{C}$ was $200 \mathrm{mM} \mathrm{NaOH}$ with $170 \mathrm{mM}$ $\mathrm{Na}$ acetate. The following program was employed to resolve monosaccharides present in the different samples: $7 \mathrm{~min}$ prewash with $60 \% \mathrm{~B}, 40 \% \mathrm{C}\left(1 \mathrm{ml} \mathrm{min}^{-1}\right), 7 \mathrm{~min}$ of column calibration with $100 \% \mathrm{~A}\left(1 \mathrm{ml} \mathrm{min}{ }^{-1}\right)$; sample injection, 0 to

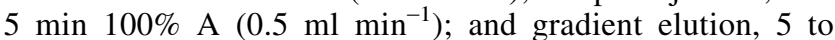

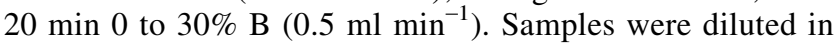
water to a volume of $50 \mu \mathrm{l}, 2 \mu \mathrm{l}$ of which were injected onto the column.

\section{ACKNOWLEDGMENTS}

This work was supported by a grant to V. Bulone from the Swedish Research Council FORMAS (grant number 2013-1427).

\section{LITERATURE CITED}

Akeley, R. V., Mills, W. R., Cunningham, C. E., and Watts, J. 1968. Lenape: A new potato variety high in solids and chipping quality. Am. Potato J. 45:142-145.

Andreu, A., Oliva, C., Distel, S., and Daleo, G. 2001. Production of phytoalexins, glycoalkaloids and phenolics in leaves and tubers of potato cultivars with different degrees of field resistance after infection with Phytophthora infestans. Potato Res. 44:1-9.

Andrivon, D., Corbière, R., Lucas, J.-M., Pasco, C., Gravoueille, J.-M., Pellé, R., Dantec, J.-P., and Ellissèche, D. 2003. Resistance to late blight and soft rot in six potato progenies and glycoalkaloid contents in the tubers. Am. J. Potato Res. 80:125-134.

Augustin, J. M., Kuzina, V., Andersen, S. B., and Bak, S. 2011. Molecular activities, biosynthesis and evolution of triterpenoid saponins. Phytochemistry 72:435-457.

Axel, C., Zannini, E., Coffey, A., Guo, J., Waters, D. M., and Arendt, E. K. 2012. Ecofriendly control of potato late blight causative agent and the potential role of lactic acid bacteria: A review. Appl. Microbiol. Biotechnol. 96:37-48.

Bergeron, D., Bushway, R. J., Storch, R. H., Alford, A. R., and Bushway, A. A. 1988. The extraction and partial purification of a rhamnosidase from Colorado potato beetle larvae (Leptinotarsa decemlineata (Say)). Am. Potato J. 65:67-74.

Bradford, M. M. 1976. A rapid and sensitive method for the quantitation of microgram quantities of protein utilizing the principle of protein-dye binding. Anal. Biochem. 72:248-254.

Brouwer, H., Coutinho, P. M., Henrissat, B., and de Vries, R. P. 2014 Carbohydrate-related enzymes of important Phytophthora plant pathogens. Fungal Genet. Biol. 72:192-200.

Byrne, J. T., Maher, N. J., and Jones, P. W. 2001. Comparative responses of Globodera rostochiensis and G. pallida to hatching chemicals. J. Nematol. 33:195-202.

Carlson-Nilsson, U., Zoteyeva, N., and Reslow, F. 2011. Glycoalkaloid content in potato tubers with different levels of resistance to Phytophthora infestans. PPO-Special Report no. 15 Thirteenth EuroBlight Workshop, St. Petersburg, Russia.

Caspi, R., Altman, T., Billington, R., Dreher, K., Foerster, H., Fulcher, C. A. Holland, T. A., Keseler, I. M., Kothari, A., Kubo, A., Krummenacker, M., Latendresse, M., Mueller, L. A., Ong, Q., Paley, S., Subhraveti, P., Weaver, D. S., Weerasinghe, D., Zhang, P., and Karp, P. D. 2014. The MetaCyc database of metabolic pathways and enzymes and the BioCyc collection of pathway/genome databases. Nucleic Acids Res. 42:D459-D471.

Choi, S. H., Lee, S. H., Kim, H. J., Lee, I. S., Kozukue, N., Levin, C. E., and Friedman, M. 2010. Changes in free amino acid, phenolic, chlorophyll, carotenoid, and glycoalkaloid contents in tomatoes during 11 stages of growth and inhibition of cervical and lung human cancer cells by green tomato extracts. J. Agric. Food Chem. 58:7547-7556.

Claringbold, W. D., Few, J. D., and Renwick, J. H. 1982. Kinetics and retention of solanidine in man. Xenobiotica 12:293-302.

Cushnie, T. P., Cushnie, B., and Lamb, A. J. 2014. Alkaloids: An overview of their antibacterial, antibiotic-enhancing and antivirulence activities Int. J. Antimicrob. Agents 44:377-386

Deahl, K. L., Young, R. J., and Sinden, S. L. 1973. A study of the relationship of late blight resistance to glycoalkaloid content in fifteen potato clones. Am. Potato J. 50:248-253.

Fattorusso, E., and Taglialatela-Scafati, O. 2007. Ecological roles of alkaloids; Alkaloids and the bitter taste. In: Modern Alkaloids: Structure, Isolation, Synthesis, and Biology. Wiley-VCH, Weinheim, Germany.

Fawke, S., Doumane, M., and Schornack, S. 2015. Oomycete interactions with plants: Infection strategies and resistance principles. Microbiol. Mol. Biol. Rev. 79:263-280.

Feng, B., Hu, W., Ma, B.-P., Wang, Y.-Z., Huang, H.-Z., Wang, S.-Q., and Qian, X.-H. 2007. Purification, characterization, and substrate specificity of a glucoamylase with steroidal saponin-rhamnosidase activity from Curvularia lunata. Appl. Microbiol. Biotechnol. 76:1329-1338.

Ferreres, F., Taveira, M., Gil-Izquierdo, A., Oliveira, L., Teixeira, T., Valentão, P., Simões, N., and Andrade, P. B. 2011. High-performance liquid chromatography-diode array detection-electrospray ionization multi-stage mass spectrometric screening of an insect/plant system: The case of Spodoptera littoralis/Lycopersicon esculentum phenolics and alkaloids. Rapid Commun. Mass Spectrom. 25:1972-1980.

Fewell, A. M., and Roddick, J. G. 1997. Potato glycoalkaloid impairment of fungal development. Mycol. Res. 101:597-603. 
Filadelfi, M. A., and Zitnak, A. 1983. A simple TLC standard for identification of potato glycoalkaloids. Can. Inst. Food Sci. Technol. J. 16:151-153.

Friedman, M. 2002. Tomato glycoalkaloids: Role in the plant and in the diet. J. Agric. Food Chem. 50:5751-5780.

Friedman, M. 2004. Analysis of biologically active compounds in potatoes (Solanum tuberosum), tomatoes (Lycopersicon esculentum), and jimson weed (Datura stramonium) seeds. J. Chromatogr. A 1054:143-155.

Friedman, M., Lee, K. R., Kim, H. J., Lee, I. S., and Kozukue, N. 2005. Anticarcinogenic effects of glycoalkaloids from potatoes against human cervical, liver, lymphoma, and stomach cancer cells. J. Agric. Food Chem. 53:6162-6169.

Friedman, M., McDonald, G. M., and Filadelfi-Keszi, M. 1997. Potato glycoalkaloids: Chemistry, analysis, safety, and plant physiology. Crit. Rev. Plant Sci. 16:55-132.

Fry, W. 2008. Phytophthora infestans: The plant (and $R$ gene) destroyer. Mol. Plant Pathol. 9:385-402.

Ginzberg, I., Tokuhisa, J. G., and Veilleux, R. E. 2009. Potato steroidal glycoalkaloids: Biosynthesis and genetic manipulation. Potato Res. 52:1-15.

Götz, S., Arnold, R., Sebastián-León, P., Martín-Rodríguez, S., Tischler, P., Jehl, M. A., Dopazo, J., Rattei, T., and Conesa, A. 2011. B2G-FAR, a species-centered GO annotation repository. Bioinformatics 27:919-924.

Haas, B. J., Kamoun, S., Zody, M. C., Jiang, R. H., Handsaker, R. E., Cano, L. M., Grabherr, M., Kodira, C. D., Raffaele, S., Torto-Alalibo, T., Bozkurt, T. O., Ah-Fong, A. M., Alvarado, L., Anderson, V. L., Armstrong, M. R., Avrova, A., Baxter, L., Beynon, J., Boevink, P. C., Bollmann, S. R., Bos, J. I., Bulone, V., Cai, G., Cakir, C., Carrington, J. C., Chawner, M., Conti, L., Costanzo, S., Ewan, R., Fahlgren, N., Fischbach, M. A., Fugelstad, J., Gilroy, E. M., Gnerre, S., Green, P. J., Grenville-Briggs, L. J., Griffith, J., Grünwald, N. J., Horn, K., Horner, N. R., Hu, C. H., Huitema, E., Jeong, D. H., Jones, A. M., Jones, J. D., Jones, R. W., Karlsson, E. K., Kunjeti, S. G., Lamour, K., Liu, Z., Ma, L., Maclean, D., Chibucos, M. C., McDonald, H., McWalters, J., Meijer, H. J., Morgan, W., Morris, P. F., Munro, C. A., O’Neill, K., OspinaGiraldo, M., Pinzón, A., Pritchard, L., Ramsahoye, B., Ren, Q., Restrepo, S., Roy, S., Sadanandom, A., Savidor, A., Schornack, S., Schwartz, D. C., Schumann, U. D., Schwessinger, B., Seyer, L., Sharpe, T., Silvar, C., Song, J., Studholme, D. J., Sykes, S., Thines, M., van de Vondervoort, P. J., Phuntumart, V., Wawra, S., Weide, R., Win, J., Young, C., Zhou, S., Fry, W., Meyers, B. C., van West, P., Ristaino, J., Govers, F., Birch, P. R., Whisson, S. C., Judelson, H. S., and Nusbaum, C. 2009. Genome sequence and analysis of the Irish potato famine pathogen Phytophthora infestans. Nature 461:393-398.

Harris, H., and Whittaker, M. 1962. Differential inhibition of the serum cholinesterase phenotypes by solanine and solanidine. Ann. Hum. Genet. 26:73-76.

Harvey, M. H., McMillan, M., Morgan, M. R. A., and Chan, H. W. S. 1985. Solanidine is present in sera of healthy individuals and in amounts dependent on their dietary potato consumption. Hum. Toxicol. 4:187-194.

Hellenäs, K.-E., Branzell, C., Johnsson, H., and Slanina, P. 1995. High levels of glycoalkaloids in the established swedish potato variety magnum bonum. J. Sci. Food Agric. 68:249-255.

Hellenäs, K. E., Nyman, A., Slanina, P., Lööf, L., and Gabrielsson, J. 1992. Determination of potato glycoalkaloids and their aglycone in blood serum by high-performance liquid chromatography. Application to pharmacokinetic studies in humans. J. Chromatogr. 573:69-78.

Heretsch, P., and Giannis, A. 2015. Chapter four-The Veratrum and Solanum alkaloids. Alkaloids Chem. Biol. 74:201-232.

Holland, H. L., and Taylor, G. J. 1979. Transformations of steroids and the steroidal alkaloid, solanine, by Phytophthora infestans. Phytochemistry 18:437-440.

Itkin, M., Rogachev, I., Alkan, N., Rosenberg, T., Malitsky, S., Masini, L., Meir, S., Iijima, Y., Aoki, K., de Vos, R., Prusky, D., Burdman, S., Beekwilder, J., and Aharoni, A. 2011. GLYCOALKALOID METABOLISM1 is required for steroidal alkaloid glycosylation and prevention of phytotoxicity in tomato. Plant Cell 23:4507-4525.

Ito, S., Ihara, T., Tamura, H., Tanaka, S., Ikeda, T., Kajihara, H., Dissanayake, C., Abdel-Motaal, F. F., and El-Sayed, M. A. 2007. $\alpha$-Tomatine, the major saponin in tomato, induces programmed cell death mediated by reactive oxygen species in the fungal pathogen Fusarium oxysporum. FEBS Lett. 581:3217-3222.

Jiang, Q.-W., Chen, M.-W., Cheng, K.-J., Yu, P.-Z., Wei, X., and Shi, Z. 2016. Therapeutic potential of steroidal alkaloids in cancer and other diseases. Med. Res. Rev. 36:119-143.

Judelson, H. S., and Blanco, F. A. 2005. The spores of Phytophthora: Weapons of the plant destroyer. Nat. Rev. Microbiol. 3:47-58.

Kamoun, S., Furzer, O., Jones, J. D. G., Judelson, H. S., Ali, G. S., Dalio, R. J. D., Roy, S. G., Schena, L., Zambounis, A., Panabières, F., Cahill,
D., Ruocco, M., Figueiredo, A., Chen, X.-R., Hulvey, J., Stam, R., Lamour, K., Gijzen, M., Tyler, B. M., Grünwald, N. J., Mukhtar, M. S., Tomé, D. F. A., Tör, M., Van Den Ackerveken, G., McDowell, J., Daayf, F., Fry, W. E., Lindqvist-Kreuze, H., Meijer, H. J. G., Petre, B., Ristaino, J., Yoshida, K., Birch, P. R. J., and Govers, F. 2015. The top 10 oomycete pathogens in molecular plant pathology. Mol. Plant Pathol. 16:413-434.

Kaup, O., Gräfen, I., Zellermann, E. M., Eichenlaub, R., and Gartemann, K. H. 2005. Identification of a tomatinase in the tomato-pathogenic actinomycete Clavibacter michiganensis subsp. michiganensis NCPPB382. Mol. Plant-Microbe Interact. 18:1090-1098.

Keukens, E. A., de Vrije, T., Fabrie, C. H., Demel, R. A., Jongen, W. M., and de Kruijff, B. 1992. Dual specificity of sterol-mediated glycoalkaloid induced membrane disruption. Biochim. Biophys. Acta 1110: 127-136.

Keukens, E. A., de Vrije, T., Jansen, L. A., de Boer, H., Janssen, M., de Kroon, A. I., Jongen, W. M., and de Kruijff, B. 1996. Glycoalkaloids selectively permeabilize cholesterol containing biomembranes. Biochim. Biophys. Acta 1279:243-250.

Keukens, E. A., de Vrije, T., van den Boom, C., de Waard, P., Plasman, H. H., Thiel, F., Chupin, V., Jongen, W. M., and de Kruijff, B. 1995. Molecular basis of glycoalkaloid induced membrane disruption. Biochim. Biophys. Acta 1240:216-228.

Kim, K. S., and Judelson, H. S. 2003. Sporangium-specific gene expression in the oomycete phytopathogen Phytophthora infestans. Eukaryot. Cell 2:1376-1385

Korpan, Y. I., Nazarenko, E. A., Skryshevskaya, I. V., Martelet, C., Jaffrezic-Renault, N., and El'skaya, A. V. 2004. Potato glycoalkaloids: True safety or false sense of security? Trends Biotechnol. 22: 147-151.

Krits, P., Fogelman, E., and Ginzberg, I. 2007. Potato steroidal glycoalkaloid levels and the expression of key isoprenoid metabolic genes. Planta 227:143-150.

Lamberth, C., Jeanmart, S., Luksch, T., and Plant, A. 2013. Current challenges and trends in the discovery of agrochemicals. Science 341: 742-746.

Lee, M. R. 2007. Solanaceae IV: Atropa belladonna, deadly nightshade. J. R. Coll. Physicians Edinb. 37:77-84.

Lin, F., and Wang, R. 2010. Hemolytic mechanism of dioscin proposed by molecular dynamics simulations. J. Mol. Model. 16:107-118.

Liu, T., Yu, H., Zhang, C., Lu, M., Piao, Y., Ohba, M., Tang, M., Yuan, X., Wei, S., Wang, K., Ma, A., Feng, X., Qin, S., Mukai, C., Tsuji, A., and Jin, F. 2012. Aspergillus niger DLFCC-90 rhamnoside hydrolase, a new type of flavonoid glycoside hydrolase. Appl. Environ. Microbiol. 78: 4752-4754.

Lombard, V., Golaconda Ramulu, H., Drula, E., Coutinho, P. M., and Henrissat, B. 2014. The carbohydrate-active enzymes database (CAZy) in 2013. Nucleic Acids Res. 42:D490-D495.

Manrique-Moreno, M., Londoño-Londoño, J., Jemioła-Rzemińska, M., Strzałka, K., Villena, F., Avello, M., and Suwalsky, M. 2014. Structural effects of the Solanum steroids solasodine, diosgenin and solanine on human erythrocytes and molecular models of eukaryotic membranes. Biochim. Biophys. Acta 1838 (1 Pt B):266-277.

Martin-Hernandez, A. M., Dufresne, M., Hugouvieux, V., Melton, R., and Osbourn, A. 2000. Effects of targeted replacement of the tomatinase gene on the interaction of Septoria lycopersici with tomato plants. Mol. Plant-Microbe Interact. 13:1301-1311.

McCue, K. F., Allen, P. V., Shepherd, L. V., Blake, A., Maccree, M. M., Rockhold, D. R., Novy, R. G., Stewart, D., Davies, H. V., and Belknap, W. R. 2007. Potato glycosterol rhamnosyltransferase, the terminal step in triose side-chain biosynthesis. Phytochemistry 68:327-334.

McCue, K. F., Allen, P. V., Shepherd, L. V., Blake, A., Whitworth, J., Maccree, M. M., Rockhold, D. R., Stewart, D., Davies, H. V., and Belknap, W. R. 2006. The primary in vivo steroidal alkaloid glucosyltransferase from potato. Phytochemistry 67:1590-1597.

Medina, J. M., Rodrigues, J. C. F., Moreira, O. C., Atella, G., Souza, Wd., and Barrabin, H. 2015. Mechanisms of growth inhibition of Phytomonas serpens by the alkaloids tomatine and tomatidine. Mem. Inst. Oswaldo Cruz 110:48-55.

Mensinga, T. T., Sips, A. J. A. M., Rompelberg, C. J. M., van Twillert, K., Meulenbelt, J., van den Top, H. J., and van Egmond, H. P. 2005. Potato glycoalkaloids and adverse effects in humans: An ascending dose study. Regul. Toxicol. Pharmacol. 41:66-72.

Milner, S. E., Brunton, N. P., Jones, P. W., O’Brien, N. M., Collins, S. G., and Maguire, A. R. 2011. Bioactivities of glycoalkaloids and their aglycones from Solanum species. J. Agric. Food Chem. 59:3454-3484.

Moehs, C. P., Allen, P. V., Friedman, M., and Belknap, W. R. 1997. Cloning and expression of solanidine UDP-glucose glucosyltransferase from potato. Plant J. 11:227-236. 
Munafo, J. P., Jr., and Gianfagna, T. J. 2011. Antifungal activity and fungal metabolism of steroidal glycosides of Easter lily (Lilium longiflorum Thunb.) by the plant pathogenic fungus, Botrytis cinerea. J. Agric. Food Chem. 59:5945-5954.

Munafo, J. P., Jr., and Gianfagna, T. J. 2015. Chemistry and biological activity of steroidal glycosides from the Lilium genus. Nat. Prod. Rep. 32:454-477

Nenaah, G. 2010. Individual and synergistic toxicity of solanaceous glycoalkaloids against two coleopteran stored-product insects. J. Pest Sci. 84:77-86.

Nowicki, M., Fooled, M. R., Nowakowska, M., and Kozik, E. U. 2012. Potato and tomato late blight caused by Phytophthora infestans: An overview of pathology and resistance breeding. Plant Dis. 96:4-17.

Oda, Y., Saito, K., Ohara-Takada, A., and Mori, M. 2002. Hydrolysis of the potato glycoalkaloid $\alpha$-chaconine by filamentous fungi. J. Biosci. Bioeng. 94:321-325.

Ohyama, K., Okawa, A., Moriuchi, Y., and Fujimoto, Y. 2013. Biosynthesis of steroidal alkaloids in Solanaceae plants: Involvement of an aldehyde intermediate during C-26 amination. Phytochemistry 89:26-31.

Ökmen, B., Etalo, D. W., Joosten, M. H., Bouwmeester, H. J., de Vos, R. C. H., Collemare, J., and de Wit, P. J. 2013. Detoxification of $\alpha$-tomatine by Cladosporium fulvum is required for full virulence on tomato. New Phytol. 198:1203-1214.

Ospina-Giraldo, M. D., Griffith, J. G., Laird, E. W., and Mingora, C. 2010. The CAZyome of Phytophthora spp.: A comprehensive analysis of the gene complement coding for carbohydrate-active enzymes in species of the genus Phytophthora. BMC Genomics 11:525.

Oyarzun, P. J., Pozo, A., Ordoñez, M. E., Doucett, K., and Forbes, G. A. 1998. Host Specificity of Phytophthora infestans on tomato and potato in Ecuador. Phytopathology 88:265-271.

Pareja-Jaime, Y., Roncero, M. I., and Ruiz-Roldán, M. C. 2008. Tomatinase from Fusarium oxysporum $\mathrm{f}$. sp. lycopersici is required for full virulence on tomato plants. Mol. Plant-Microbe Interact. 21:728-736.

Petersen, T. N., Brunak, S., von Heijne, G., and Nielsen, H. 2011. SignalP 4.0: Discriminating signal peptides from transmembrane regions. Nat. Methods 8:785-786.

Petersson, E. V., Arif, U., Schulzova, V., Krtková, V., Hajšlová, J., Meijer, J., Andersson, H. C., Jonsson, L., and Sitbon, F. 2013a. Glycoalkaloid and calystegine levels in table potato cultivars subjected to wounding, light, and heat treatments. J. Agric. Food Chem. 61:5893-5902.

Petersson, E. V., Nahar, N., Dahlin, P., Broberg, A., Tröger, R., Dutta, P. C., Jonsson, L., and Sitbon, F. 2013b. Conversion of exogenous cholesterol into glycoalkaloids in potato shoots, using two methods for sterol solubilisation. PLoS One 8:e82955.

R Core Team. 2012. R: A language and environment for statistical computing. Foundation for Statistical Computing, Vienna, Austria.

Roddick, J. G. 1979. Complex formation between solanaceous steroidal glycoalkaloids and free sterols in vitro. Phytochemistry 18:1467-1470.

Roddick, J. G. 1989. The acetylcholinesterase-inhibitory activity of steroidal glycoalkaloids and their aglycones. Phytochemistry 28:2631-2634.
Roddick, J. G., and Rijnenberg, A. L. 1986. Effect of steroidal glycoalkaloids of the potato on the permeability of liposome membranes. Physiol. Plant. 68:436-440.

Russell, P. E. 2005. A century of fungicide evolution. J. Agric. Sci. 143:11-25.

Sandrock, R. W., and VanEtten, H. D. 1998. Fungal sensitivity to and enzymatic degradation of the phytoanticipin $\alpha$-tomatine. Phytopathology 88:137-143.

Sandrock, R. W., and VanEtten, H. D. 2001. The relevance of tomatinase activity in pathogens of tomato: Disruption of the $\beta 2$-tomatinase gene in Colletotrichum coccodes and Septoria lycopersici and heterologous expression of the Septoria lycopersici $\beta 2$-tomatinase in Nectria haematococca, a pathogen of tomato fruit. Physiol. Mol. Plant Pathol. 58:159-171.

Sanford, L. L., Deahl, K. L., Sinden, S. L., and Ladd, T. L. 1992. Glycoalkaloid contents in tubers from Solanum tuberosum populations selected for potato leafhopper resistance. Am. Potato J. 69:693-703.

Sarquís, J. I., Coria, N. A., Aguilar, I., and Rivera, A. 2000. Glycoalkaloid content in Solanum species and hybrids from a breeding program for resistance to late blight (Phytophthora infestans). Am. J. Potato Res. 77: 295-302.

Seipke, R. F., and Loria, R. 2008. Streptomyces scabies 87-22 possesses a functional tomatinase. J. Bacteriol. 190:7684-7692.

Simonovska, B., and Vovk, I. 2000. High-performance thin-layer chromatographic determination of potato glycoalkaloids. J. Chromatogr. A 903: 219-225.

Simons, V., Morrissey, J. P., Latijnhouwers, M., Csukai, M., Cleaver, A., Yarrow, C., and Osbourn, A. 2006. Dual effects of plant steroidal alkaloids on Saccharomyces cerevisiae. Antimicrob. Agents Chemother. 50:2732-2740.

Sinden, S. L., Goth, R. W., and O'Brien, M. J. 1973. Effect of potato alkaloids on the growth of Alternaria solani and their possible role as resistance factors in potatoes. Phytopathology 63:303-307.

Sinden, S. L., and Webb, R. E. 1974:Pages 1-30 in: Effect of environment on glycoalkaloid content of six potato varieties at 39 locations Agricultural Research Service, U.S. U.S. Department of Agriculture, Washington, D.C.

Weltring, K.-M., Wessels, J., and Geyer, R. 1997. Metabolism of the potato saponins $\alpha$-chaconine and $\alpha$-solanine by Gibberella pilicaris. Phytochemistry 46:1005-1009.

Yadav, V., Yadav, P. K., Yadav, S., and Yadav, K. D. S. 2010. $\alpha-$ LRhamnosidase: A review. Process Biochem. 45:1226-1235.

Zhao, S., and Fernald, R. D. 2005. Comprehensive algorithm for quantitative real-time polymerase chain reaction. J. Comput. Biol. 12: 1047-1064.

Zitnak, A., and Johnston, G. R. 1970. Glycoalkaloid content of B5141-6 potatoes. Am. Potato J. 47:256-260.

\section{AUTHOR-RECOMMENDED INTERNET RESOURCE}

The American Oil Chemists' Society's AOCS Lipid Library: http://lipidlibrary.aocs.org 